\title{
Characterization of shallow oceanic precipitation using profiling and scanning radar observations at the Eastern North Atlantic ARM observatory
}

\author{
Katia Lamer ${ }^{1}$, Bernat Puigdomènech Treserras ${ }^{2}$, Zeen Zhu ${ }^{3}$, Bradley Isom ${ }^{4}$, Nitin Bharadwaj ${ }^{4}$, and Pavlos Kollias ${ }^{3,5}$ \\ ${ }^{1}$ Department of Earth and Atmospheric Science, The City College of New York, New York, USA \\ ${ }^{2}$ Department of Atmospheric and Oceanic Sciences, McGill University, Montréal, Canada \\ ${ }^{3}$ School of Marine and Atmospheric Sciences, Stony Brook University, Stony Brook, USA \\ ${ }^{4}$ Atmospheric Measurement and Data Sciences, Pacific Northwest National Laboratory, Richland, USA \\ ${ }^{5}$ Department of Environmental and Climate Sciences, Brookhaven National Laboratory, Upton, USA
}

Correspondence: Katia Lamer (klamer@ccny.cuny.edu)

Received: 15 April 2019 - Discussion started: 18 April 2019

Revised: 19 July 2019 - Accepted: 6 August 2019 - Published: 11 September 2019

\begin{abstract}
Shallow oceanic precipitation variability is documented using three second-generation radar systems located at the Atmospheric Radiation Measurement (ARM) Eastern North Atlantic observatory: ARM zenith radar (KAZR2), the Ka-band scanning ARM cloud radar (KaSACR2) and the Xband scanning ARM precipitation radar (XSAPR2). First, the radar systems and measurement post-processing techniques, including sea-clutter removal and calibration against colocated disdrometer and Global Precipitation Mission (GPM) observations are described. Then, we present how a combination of profiling radar and lidar observations can be used to estimate adaptive (in both time and height) parameters that relate radar reflectivity $(Z)$ to precipitation rate $(R)$ in the form $Z=\alpha R^{\beta}$, which we use to estimate precipitation rate over the domain observed by XSAPR2. Furthermore, constant altitude plan position indicator (CAPPI) gridded XSAPR2 precipitation rate maps are also constructed.

Hourly precipitation rate statistics estimated from the three radar systems differ because KAZR2 is more sensitive to shallow virga and XSAPR2 suffers from less attenuation than KaSACR2 and as such is best suited for characterizing intermittent and mesoscale-organized precipitation. Further analysis reveals that precipitation rate statistics obtained by averaging $12 \mathrm{~h}$ of KAZR2 observations can be used to approximate that of a $40 \mathrm{~km}$ radius domain averaged over similar time periods. However, it was determined that KAZR2 is unsuitable for characterizing domain-averaged precipitation rate over shorter periods. But even more fundamentally, these
\end{abstract}

results suggest that these observations cannot produce an objective domain precipitation estimate and that the simultaneous use of forward simulators is desirable to guide model evaluation studies.

\section{Introduction}

Characterizing shallow oceanic precipitation is very important for improving our understanding of shallow cloud systems since precipitation is related to a number of cloud processes, all of which may affect cloud properties. For example, precipitation leads to a reduction in the droplet number via the collision-coalescence process and of the liquid water path through sedimentation. Furthermore, a number of modeling studies have suggested that drizzle organization, intensity and subcloud layer evaporation could play a role in organizing stratocumulus cloud decks on the mesoscale (Zhou et al., 2017, 2018; Savic-Jovcic and Stevens, 2008; Wang and Feingold, 2009; Yamaguchi and Feingold, 2015). Ultimately, these controls may alter low-cloud radiative properties and climate (Wood, 2012). Quantification of marine drizzle cell precipitation rate and environmental conditions over a domain of several kilometers could provide additional observational constraints for modeling studies. Unfortunately, collecting such observations remains challenging over the ocean. 
Although satellite-based microwave sensors can infer the spatial distribution of liquid water path (Wood and Hartmann, 2006; Miller and Yuter, 2013) and precipitation rate (Ellis et al., 2009; Adler et al., 2009; Rapp et al., 2013), they have poor horizontal resolution and suffer from surface inference, causing them to under-sample the cloud field variability and to underreport boundary layer cloud and precipitation occurrence (Schumacher and Houze, 2000; Rapp et al., 2013). In contrast, airborne (Stevens et al., 2005; Wood et al., 2011; Moyer and Young, 1994; Vali et al., 1998; Paluch and Lenschow, 1991; Sharon et al., 2006) and ship-based (Yuter et al., 2000; Comstock et al., 2005; Feingold et al., 2010) sensors can resolve the spatial and temporal variability of the cloud and precipitation field, but field campaigns deploying such sensors are often expensive to conduct and limited in temporal duration (Stevens et al., 2003; Bretherton et al., 2004; Rauber et al., 2007). Island-based observatories, such as the U.S. Department of Energy (DOE) Atmospheric Radiation Measurement (ARM) Eastern North Atlantic observatory (ENA, Mather et al., 2016; Kollias et al., 2016) and the Barbados Cloud Observatory (BCO, Lamer et al., 2015; Stevens et al., 2016), operating profiling and scanning remote sensors can provide long-term statistics of marine light precipitation.

Beyond detecting rain, quantifying the spectrum from drizzle to rain is especially challenging since at small rates droplets are mostly spherical and as such do not generate the typical polarimetric signals required of common precipitation rate retrievals (e.g., Villarini and Krajewski, 2010; Gorgucci et al., 2000). As an alternative to polarimetric signatures, a combination of sensors is typically required to retrieve precipitation rate $(R)$. Combinations of radar reflectivity $(Z)$ and in situ measurements have led to the development of $Z-R$ relationships (Wood, 2005; Comstock et al., 2004; VanZanten et al., 2005; Vali et al., 1998); however, these tend not to be universally applicable since they are based on assumptions about the drizzle particle size distribution, which may vary with factors such as aerosol loading and liquid water path. Moreover, relying on surface disdrometer measurements to characterize warm precipitation may be especially unsuitable at the ENA where (i) a large fraction of the precipitation does not reach the surface (Yang et al., 2018), (ii) precipitation reaching the ground typically does so with an intensity below the detection limit of most optical-based disdrometers $\left(\sim 10^{-2} \mathrm{~mm} \mathrm{~h}^{-1}\right)$ and (iii) evaporation is an active process such that water drop size distribution information retrieved at one height may not be appropriate to represent the entire atmospheric column. Alternatively, a method combining radar reflectivity and lidar backscatter measurements has been proposed to retrieve $R$ with fewer assumptions about the drizzle particle size distribution (Intrieri et al., 1993; O'Connor et al., 2005). Because of the current rarity of scanning lidar observations, this technique has only been used to retrieve $R$ in the column and cannot be used to address concerns present in recent studies suggesting that scanning systems are essential to map domain properties (Oue et al., 2016).

Here we propose exploiting the availability of colocated vertically pointing radar and lidar, as well as scanning radar systems, to characterize marine precipitation rate variability over a domain of 40-60 km around the ENA observatory. The eastern North Atlantic region, with its abundance of marine boundary layer precipitating clouds, is an ideal location for such study (Rémillard and Tselioudis, 2015; Wood, 2012). Observations from the Ka-band ARM zenith radar (KAZR2) and zenith-pointing ceilometer lidar are combined to estimate adaptive (both in time and height) $Z-R$ relationships, which we then use to estimate precipitation rate across the domain observed by the X-band scanning ARM precipitation radar (XSAPR2). Domain-averaged and time-averaged precipitation rate estimates obtained from zenith-pointing and scanning observations are compared to document the complementarity and applicability of each sensor in documenting precipitation rate from warm boundary layer clouds.

\section{Eastern North Atlantic observatory}

In October 2013, the ARM program established a permanent observatory in the eastern North Atlantic on the island of Graciosa $\left(\sim 60 \mathrm{~km}^{2}\right.$ area; $\left.39.1^{\circ} \mathrm{N}, 28.0^{\circ} \mathrm{W}\right)$. The site, located in the Azores archipelago, straddles the boundary between the subtropics and the midlatitudes and as such is subject to a wide range of different meteorological conditions, including periods of relatively undisturbed trade wind flow, midlatitude cyclonic systems and associated fronts, and periods of extensive low-level cloudiness (Rémillard and Tselioudis, 2015). The observatory hosts an extensive instrument suite, including three second-generation radar systems: the Ka-band ARM zenith radar (KAZR2), the dualfrequency Ka-band and W-band scanning ARM cloud radar (SACR2) and the X-band scanning ARM precipitation radar (XSAPR2), the specifications of which are listed in Table 1. A short description of the radar systems is provided here with emphasis on changes in configuration from the first to the second generation.

\section{$2.1 \quad$ KAZR2}

KAZR2 operates at $34.8 \mathrm{GHz}(\lambda=8.6 \mathrm{~mm})$ and is an upgraded version of the KAZR that replaced the ARM millimeter cloud radar (MMCR, Kollias et al., 2016). KAZR2 uses an extended interaction Klystron (EIK) amplifier with a $2.2 \mathrm{~kW}$ peak power and $5 \%$ duty cycle. Its dual-receiver configuration allows for the simultaneous transmission of two pulses: (i) a long $(4 \mu$ s) pulse with frequency modulation (pulse compression) for higher sensitivity $(\sim-44 \mathrm{dBZ}$ at $1 \mathrm{~km}$ not considering signal integration gain) at ranges from $737 \mathrm{~m}$ to $18 \mathrm{~km}$ from the radar and (ii) a short pulse $(200 \mathrm{~ns})$ with a sensitivity of $(\sim-32.5 \mathrm{dBZ}$ at $1 \mathrm{~km}$ not con- 
Table 1. Specification of ARM ENA zenith and scanning second-generation radar systems.

\begin{tabular}{|c|c|c|c|c|c|}
\hline & KAZR2 & & KaSACR2 & & XSAPR2 \\
\hline Frequency (MHz) & 34860 & & 35290 & & 9500 \\
\hline Peak power $(\mathrm{kW})$ & 2.2 & & 2.2 & & 300 \\
\hline Maximum duty cycle (\%) & 5.0 & & 5.0 & & 0.1 \\
\hline Pulse compression capability & Yes and activated & & Yes but not activated & & No \\
\hline Pulse length & $200 \mathrm{~ns}$ & $4 \mu \mathrm{s}$ & $0.4 \mu \mathrm{s}$ & & $0.66 \mu \mathrm{s}$ \\
\hline Sensitivity single pulse (dBZ) & $-32.5($ at $1 \mathrm{~km})$ & $-44($ at $1 \mathrm{~km})$ & -15 (at $20 \mathrm{~km})$ & & $-21($ at $20 \mathrm{~km})$ \\
\hline Pulse (dBZ) & (at $1 \mathrm{~km})$ & (at $1 \mathrm{~km})$ & (at $20 \mathrm{~km}$ ) & & (at $20 \mathrm{~km}$ ) \\
\hline Dead zone (m) & 72 & 737 & 400 & & 100 \\
\hline Unambiguous range $(\mathrm{km})$ & 18 & & 40 & & Over 100 \\
\hline Gate spacing $(\mathrm{m})$ & 30 & & 30 & & 100 \\
\hline Antenna size (m) & 1.82 & & 1.82 & & 5.0 \\
\hline $3 \mathrm{~dB}$ beam width $\left(^{\circ}\right)$ & 0.3 & & 0.3 & & 0.45 \\
\hline Scan rate $\left({ }^{\circ} \mathrm{s}^{-1}\right)$ & - & & 3 & & 6 \\
\hline Scan strategy & Zenith & & PPI scan & & VCP scan \\
\hline Elevation angle $\left({ }^{\circ}\right)$ & 90 & & 0.5 & & 0 to 5 every 0.5 \\
\hline Azimuthal sector $\left({ }^{\circ}\right)$ & - & & 360 & & 160 \\
\hline Scan time & $2 \mathrm{~s}$ & & $2 \mathrm{~min}$ & & $5 \min$ \\
\hline Scan interval & Continuous & & $15 \mathrm{~min}$ & & Continuous \\
\hline Transmit polarization & $\mathrm{H}$ & & Alternating $\mathrm{H}$ and $\mathrm{V}$ & & Simultaneous $\mathrm{H}$ and $\mathrm{V}$ \\
\hline Received polarization & $\mathrm{H}$ and $\mathrm{V}$ & & $\mathrm{H}$ and $\mathrm{V}$ & & $\mathrm{H}$ and $\mathrm{V}$ \\
\hline Amplifier type & Klystron (EIK) & & Klystron (EIK) & & Magnetron \\
\hline Signal processing & FFT & & Pulse-pair & FFT & Pulse-pair FFT \\
\hline Doppler spectra & Yes & & No & Yes & No $\quad$ Yes \\
\hline Second-trip echo removal technique & Challenging & & Frequency hopping & Challenging & Noncoherent power technique \\
\hline $\begin{array}{l}\text { Velocity dealiasing } \\
\text { technique }\end{array}$ & Challenging & & $\begin{array}{l}\text { Staggered pulse } \\
\text { repetition time }\end{array}$ & Challenging & Continuous \\
\hline
\end{tabular}

sidering signal integration gain) at ranges from $72 \mathrm{~m}$ to $18 \mathrm{~km}$ from the radar. KAZR2 has a narrow $\left(0.3^{\circ}\right) 3 \mathrm{~dB}$ antenna bandwidth and is nominally operated with a range resolution of $30 \mathrm{~m}$ and a temporal resolution of $2 \mathrm{~s}$ and is set to record the full radar Doppler spectrum with 256 or 512 fast Fourier transform (FFT) points. KAZR2 transmits a horizontal pulse and receives both horizontal and vertical polarization such that the only polarimetric information it can measure is the linear depolarization ratio.

\subsection{SACR2}

Ka-band scanning ARM cloud radar (KaSACR2) is a fully polarimetric radar that operates at $35.3 \mathrm{GHz}(\lambda=$ $8.5 \mathrm{~mm}$ ) and is an upgraded version of the single polarization KaSACR described in Kollias et al. (2014a, b). The KaSACR2 also uses an EIK amplifier with a $2.2 \mathrm{~kW}$ peak power and has a $5 \%$ duty cycle and a $3 \mathrm{~dB}$ antenna beamwidth of $0.3^{\circ}$. Currently, it is operated with a short pulse, although it could be operated with a longer pulse with pulse compression for increased sensitivity. Owing to its narrow beam width, KaSACR2 must scan rather slowly $\left(3-6^{\circ} \mathrm{s}^{-1}\right)$ to collect observations with a sensitivity of $\sim-15 \mathrm{dBZ}$ at $20 \mathrm{~km}$ (not considering signal integration gain). The KaSACR2 conducts a cloud sampling strategy that includes different modes (Kollias et al., 2014a, b). Here, because of our interest in mapping precipitation struc- ture and rate over a large horizontal domain, we use observations collected in plan position indicator (PPI) configuration that are only available at $0.5^{\circ}$ elevation angle over a $160^{\circ}$ wide azimuth sector. The KaSACR2 conducts a PPI scan every $15 \mathrm{~min}$ and takes 2 min to collect each PPI. The KaSACR2 employs frequency hopping and staggered pulse repetition time techniques to mitigate artifacts due to secondtrip echoes and velocity aliasing. This, however, comes at the expense of preventing the collection of the full Doppler spectrum.

\subsection{XSAPR2}

The XSAPR2 operates at $9.5 \mathrm{GHz}(\lambda=3.2 \mathrm{~cm})$. It is an upgraded version of the XSAPR, as it operates with an improved digital receiver and a larger antenna $(5 \mathrm{~m})$, which results in an exceptionally narrow $3 \mathrm{~dB}$ antenna beamwidth of $0.45^{\circ}$. The requirement for the XSAPR2 to have a narrow antenna beamwidth emerged from two main needs: (i) to reduce the impact of sea clutter at low elevations and (ii) to maintain high angular resolution over a $60 \mathrm{~km}$ radius in order to resolve small-scale oceanic precipitating clouds. XSAPR2 uses a high-power Magnetron with a $300 \mathrm{~kW}$ peak power and a maximum duty cycle of $0.1 \%$. Under nominal operational conditions, the XSAPR2 transmits a $60 \mathrm{~m}$ long pulse and scans at a relatively slow rate $\left(6^{\circ} \mathrm{s}^{-1}\right)$ to collect observations with a sensitivity of $\sim-21 \mathrm{dBZ}$ at $20 \mathrm{~km}$ (not consid- 
ering integration gain). The XSAPR2 volume coverage pattern (VCP) scan strategy consists of a series of PPI scans every $0.5^{\circ}$ elevation between the angles of 0 and $5^{\circ}$. Because of considerable beam blockage in the southerly direction, a $160^{\circ}$ azimuth sector coverage is achieved. The VCP scan (i.e., the entire set of PPI scans) is completed within $5 \mathrm{~min}$ and subsequently repeated. Horizontal and vertical polarization are possible for both transmit and receive states, meaning XSAPR2 collects a full suite of polarimetric variables while in scanning mode.

\section{Radar observations post-processing}

Radar observations require considerable post-processing for the removal of non-meteorological targets before they can be scientifically interpreted or used to retrieve geophysical quantities such as precipitation rate. Radar data postprocessing is described in Sect. 3.1 and cross-comparison between different systems for calibration is described in Sect. 3.2. Note that the KAZR2 data used for analysis are from "enakazrgeC1.a1" files, KaSACR2 data are from "enakasacrppivhC1.a1" files and the XSAPR2 from the "enaxsaprsecD1.00 files". All data files were obtained from the ARM archive (https://www.archive.arm.gov/discovery/, last access: 1 September 2019).

\subsection{Removal of non-meteorological targets}

First, signal processing artifacts (e.g., second-trip echoes) and echoes of non-meteorological origin (e.g., biological echoes, sea clutter and ground clutter) are identified and removed.

The KaSACR 2 system operates in fully polarimetric mode and uses staggered pulse repetition time and frequency hopping to automatically remove second-trip echoes, perform velocity dealiasing and increase the number of independent samples (Pazmany et al., 2013). The XSAPR2 systems operates using a magnetron system that is coherent upon reception (i.e., transmitted pulse phase is random). For the XSAPR2, the removal of second-trip echoes is done using normalized coherent power (NCP), which is the coherency of the received pulse with respect to the last transmitted pulse. For atmospheric echoes within the maximum unambiguous range, NCP is high since the radar receiver is phase-locked on the phase of the last transmitted pulse. Outside of the maximum unambiguous range, NCP is low since the radar receiver has already phase-locked on the phase of another transmitted pulse. Here, an NCP threshold of 0.3 is used to identify echoes originating from outside the maximum unambiguous range (i.e., second-trip echoes).

Biological targets, such as insects and birds often contaminate radar observations, especially over land (e.g., Luke et al., 2008). Their occurrence varies with atmospheric condition, time of the year and time of the day (Alku et al., 2015).
KAZR2 observations at the ENA seem minimally impacted by biological echoes. Furthermore, the fact that the bulk of the KaSACR2 and XSAPR2 observations are collected over open ocean and that Graciosa is a small island suggests that biological targets should not be a concern at this particular location.

On the other hand, low-elevation-angle observations are susceptible to sea-clutter contamination. Research on radar sea-clutter characterization and remediation has been ongoing for over 20 years (e.g., Horst et al., 1978; Gregers-Hansen and Mital, 2009; Nathanson et al., 1991). Observational and modeling studies suggest that factors such as oceanic wave properties (related to local wind speed and direction), swell and air density streams can affect sea-clutter occurrence. Radar characteristics such as wavelength, wave polarization, beam width and grazing angle are also known to affect seaclutter characteristics and amounts and our ability to isolate atmospheric returns from sea clutter. Here, observations collected over a range of wind conditions during nearly $100 \mathrm{~h}$ of clear sky conditions are used to examine how sea-clutter characteristics vary with radar wavelength, beam width and beam elevation angle.

First, the distribution of sea-clutter reflectivities as measured by the XSAPR2 and KaSACR2 at elevation $0.5^{\circ}$ are compared to document the antenna beam width effect (Fig. 1d). The KaSACR2 ( $0.3^{\circ} 3 \mathrm{~dB}$ antenna beam width) sea-clutter reflectivity distribution is narrower with a peak at $-21 \mathrm{dBZ}$ and a majority of echoes below $-15 \mathrm{dBZ}$ (Fig. 1d black line), while the XSAPR2 $\left(0.45^{\circ} 3 \mathrm{~dB}\right.$ antenna beam width) sea-clutter reflectivity distribution is wider, peaks at $-18 \mathrm{dBZ}$ and covers a range from -40 to $+10 \mathrm{dBZ}$ (Fig. 1d red line). This can be explained by the XSAPR2 wider antenna beam width, which results in a larger fraction of the radiated energy to hit ocean waves, causing higher ocean clutter return power. Similar to beam width, elevation angle affects how much sea is in the radar field of view and the spatial extent of observed sea clutter. Figure $1 \mathrm{~d}$ shows that, at $1.0^{\circ}$ elevation, XSAPR2 sea-clutter reflectivity peaks at a lower reflectivity of $-25 \mathrm{dBZ}$ (blue line) and Fig. $1 \mathrm{~b} 3$ shows that in this configuration it frequently ( $>25 \%$ of the time) detects clutter only over a domain of $10 \mathrm{~km}$ radius around the site which is much less than it detects when collecting observations at a $0.5^{\circ}$ elevation (significant clutter in a $20 \mathrm{~km}$ radius around the site in Fig. 1a3).

Now that we have characterized sea-clutter intensity and frequency of occurrence using clear sky observations, we next evaluate its impact on the detection of meteorological targets using observations containing a mixture of hydrometeor and sea clutter. To isolate hydrometeors from clutter, we exploit the correlation coefficient $\rho_{\mathrm{HV}}$, which we know is affected by the relative occurrence of signal to clutter; $\rho_{\mathrm{HV}}$ is typically close to 1 for liquid-phase hydrometeors and lower for non-meteorological targets. Looking at KaSACR2 reflectivity and $\rho_{\mathrm{HV}}$ confirms that at Ka-band wavelength the signal-to-clutter ratio is high and hydrometeor contributions 
XSAPR2 $0.5^{\circ}$ elev.
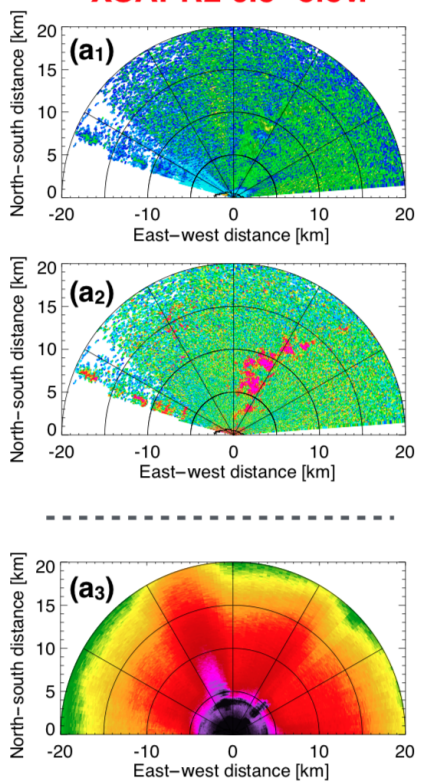

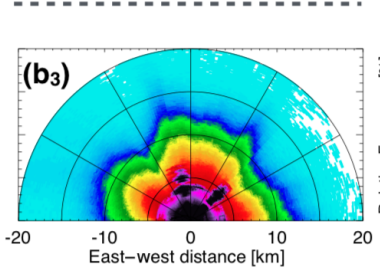

XSAPR2 $1^{\circ} \mathrm{elev}$

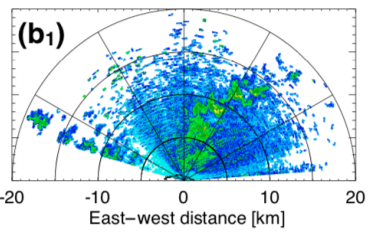

(b)
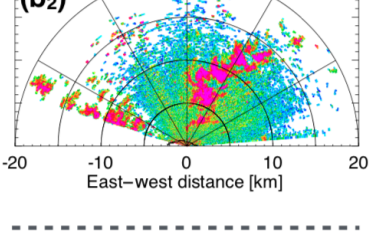

KaSACR $0.5^{\circ}$ elev.
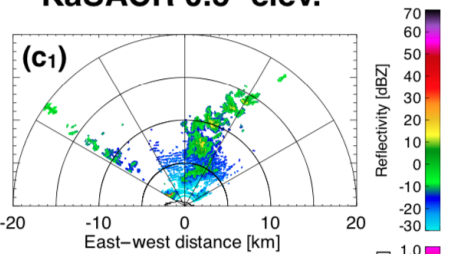

$\left(\mathbf{c}_{2}\right)$
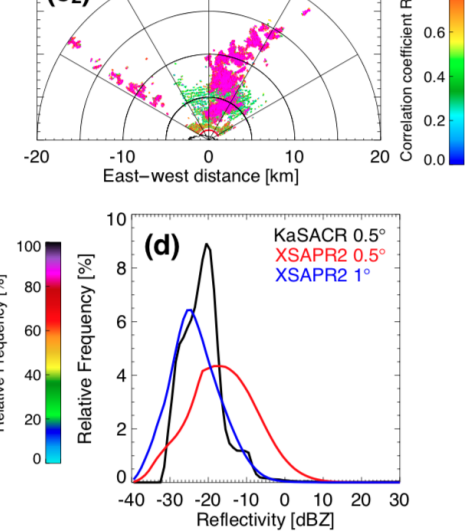

Figure 1. For significant echoes, (1) radar reflectivity, (2) correlation coefficient $\left(\rho_{\mathrm{HV}}\right)$ and (3) relative frequency of occurrence of clutter as observed by the (a) XSAPR2 at $0.5^{\circ}$ elevation, (b) XSAPR2 at $1^{\circ}$ elevation and (c) KaSACR at $0.5^{\circ}$ elevation. (d) Clutter characteristics estimated using $93 \mathrm{~h}$ of clear sky observations.

dominate both radar reflectivity and correlation coefficient measurements (Fig. 1c1 and c2, respectively). The enhanced KaSACR2 signal-to-clutter ratio is attributed to two effects: (i) its narrow beamwidth, which causes a smaller fraction of the transmitter energy to hit the sea surface, and (ii) its shorter wavelength, which creates a larger distinction between hydrometeor scattering (Rayleigh scattering $\sim 1 / \lambda^{4}$ ) and sea-clutter (scattering $\sim 1 / \lambda$ ). Using KaSACR2 observations as a guide to locate cloud and precipitation location (Fig. 1c1), it is apparent that it is not possible to distinguish atmospheric signals from sea clutter in XSAPR2 radar reflectivity observation collected at $0.5^{\circ}$ (Fig. 1a1).

Several techniques that use both time domain and frequency domain filtering methods have been proposed to discriminate between sea clutter and meteorological targets in precipitation radar observations (e.g., Torres and Zrnic, 1999; Siggia and Passarelli, 2004; Nguyen et al., 2008; Alku et al., 2015). Ryzhkov et al. (2002) present an echo classification technique based on fuzzy logic and a multiparameter dataset including radar reflectivity, mean Doppler velocity, spectrum width, differential reflectivity, differential phase, linear depolarization ratio and cross-correlation $\left(\rho_{\mathrm{HV}}\right)$. In the current study, given the radar's narrow beam width and short wavelength, an approach solely based on $\rho_{\mathrm{HV}}$ is used to filter sea clutter. Since cross-correlation between horizontal and vertical cross-polar received powers is largest for spherical hydrometeors, we label observations with $\rho_{\mathrm{HV}}$ larger than a certain threshold as atmospheric returns and the rest as sea clutter. The analysis of a large sample of $\rho_{\mathrm{HV}} \mathrm{ob}-$ servations during clear and cloudy sky conditions indicates that the use of a threshold of 0.9 for KaSACR2, and an average (over five range gates and five azimuthal measurements) threshold of 0.55 for the XSAPR2 can be used to isolate hydrometeor-dominated from clutter-dominated observations. The proposed $\rho_{\mathrm{HV}}$ technique successfully isolates atmospheric returns at the same location for both the $\mathrm{X}$ band at $1.0^{\circ}$ elevation and the reference $\mathrm{Ka}$ band at $0.5^{\circ}$ elevation (Fig. $1 b 2$ and c2, respectively, shown in pink). However, it only identifies a fraction of the atmospheric returns in the $\mathrm{X}$ band at $0.5^{\circ}$ elevation observations. There, additional filtering, beyond the scope of this study, would be required to suppress the remaining sea clutter and recover the missing atmospheric returns (see Moisseev and Chandrasekar, 2009 and Unal, 2009, who propose advanced techniques). Given this, XSAPR2 cross validation and precipitation rate maps will be estimated using observations collected at $1.0^{\circ}$ elevation since it offers the best compromise between proximity to the surface and minimum sea-clutter contamination.

\subsection{Radar calibration}

Calibrated reflectivity observations are necessary to perform quantitative precipitation rate retrievals. Following Kollias et al. (2019), KAZR2 calibration is performed using colocated surface-based Parsivel laser disdrometer equivalent radar reflectivity estimates during light precipitation events as well as CloudSat observations collected over a small radius around 

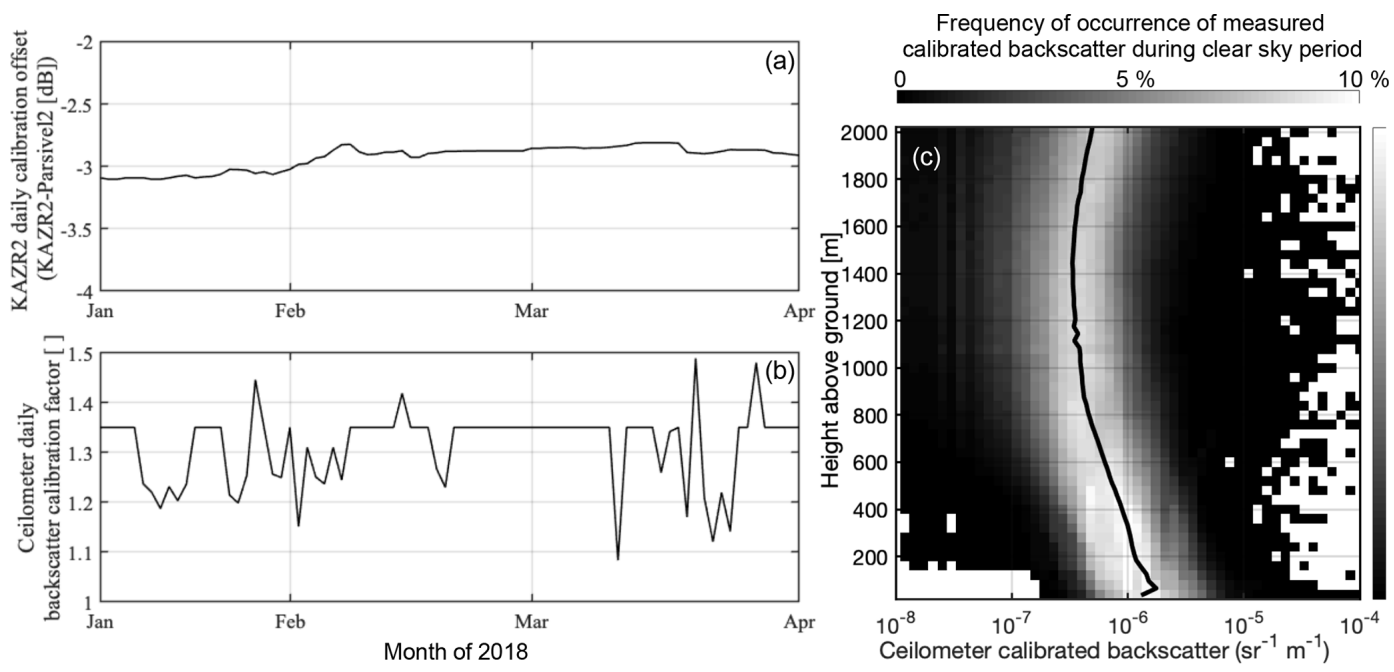

Figure 2. (a) Ka-band zenith radar (KAZR2) calibration offset to be removed from the KAZR2 radar reflectivity in order to match Parsivel disdrometer radar reflectivity estimates. (b) Ceilometer lidar calibration factor to be multiplied to observed backscatter to match theoretical liquid cloud lidar ratios. (c) Frequency of occurrence of observed backscatter during clear sky conditions, solid black line is interpreted as the mean aerosol backscatter signal, observations smaller than this threshold at each height are eliminated from the drizzle analysis.
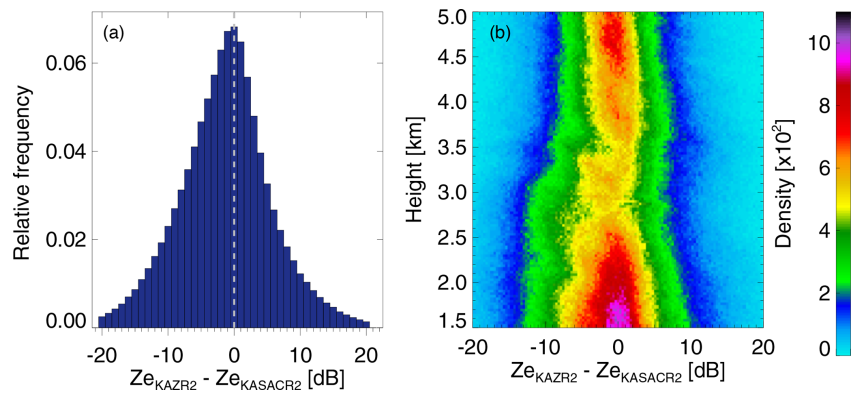

Figure 3. For the period when KAZR2 and KaSACR 2 are matched in time and range: (a) difference in radar reflectivity reported by both sensors over the ranges between 1.5 and $5.0 \mathrm{~km}$ and the (b) difference in radar reflectivity reported by both sensors as a function of range.

the site. We estimate that, during the period of interest (10 January to 1 April 2018), KAZR2 radar reflectivity measurements are off by about $+3 \mathrm{~dB}$, which we proceeded to correct for. The detailed time series of KAZR2 calibration offset is presented in Fig. 2a.

Comparison of total (Fig. 3a) and range-resolved (Fig. 3b) histograms of radar reflectivity measured by KAZR2 (precalibration) and KaSACR2 at zenith confirm that during the analysis period the KaSACR2 matched KAZR2. For this reason, KaSACR2 radar reflectivity measurements were also adjusted by the calibration constant depicted in Fig. 2a. Note how this comparison between the KAZR2 and KaSACR2 was performed between 1.5 to $5 \mathrm{~km}$ to avoid any differences in the reported radar reflectivities due to differences in how they detect ground and sea clutter.
Calibrating the XSAPR2 radar reflectivity measurements is more challenging since it does not perform profiling observations and as such it cannot be benchmarked against disdrometer and KAZR2 observations. Performing a physical subsystem calibration remains the best way to calibrate the XSAPR2 system. Prior to the ACE-ENA field campaign (June 2017) the ARM engineering team performed such a procedure, which is expected to bring the calibration of the XSAPR2 system used in this study to within $1 \mathrm{~dB}$. Here, in an effort to develop alternative calibration and cross-validation methods, we also compare the XSAPR2 radar observations to observations collected by the Global Precipitation Mission (GPM) Ku-band dual-frequency precipitation radar (DPR). Comparison is limited to periods when the satellite track crosses within a $245 \mathrm{~km}$ radius of the XSAPR2 radar site. It is not expected that both sets of observations will perfectly match because of the different footprints, path lengths and surface returns of both radar systems but this comparison should at least provide some insight in the event that the difference between both sensors is larger than several dB. For the comparison, the ground-based XSAPR2 reflectivity measurements are smoothed and interpolated to the satellite sampling volume: the azimuth-range measurements are smoothed using the $0.71^{\circ} 3 \mathrm{~dB}$ beamwidth antenna weighting function of the GPM DPR (5 km footprint). Nearest neighbor is then used to match the satellite measurements in the horizontal plane, while linear interpolation is used to match them in the vertical plane (Warren et al., 2018). Matched XSAPR2 radar reflectivity measurements are compared to GPM-DPR corrected reflectivity measurements (GPM product version V06A, Iguchi et al., 2010). Considering differences in radar sensitivity, radar reflectivity measurements 

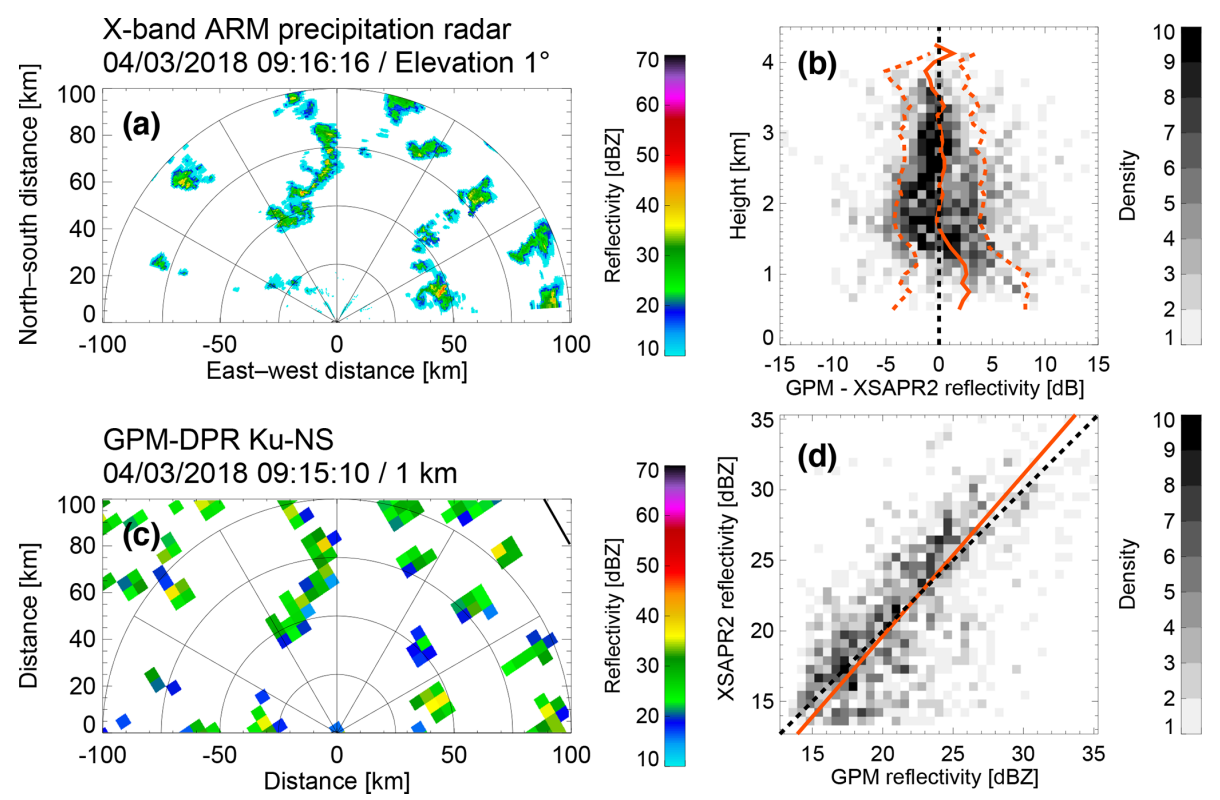

Figure 4. For the conditions that occurred on 4 March 2018 around 09:15 UTC as observed by (a) XSAPR2 radar reflectivity at $1^{\circ}$ elevation and (c) GPM-DPR Ku-band radar reflectivity at $1 \mathrm{~km}$ height. For the entire geometry-matching dataset with 1516 points used for the calibration: (b) scatter, mean (orange) and standard deviation (dashed lines) of the difference between the GPM-DPR Ku band and XSAPR2 radar reflectivity measurements as a function of height and (d) a scatterplot comparing the XSAPR2 and GPM-DPR Ku-band reflectivity measurements above the GPM surface echo height of $1.5 \mathrm{~km}$. Also plotted is the 1-to- 1 relationship (dashed line) and the best linear fit to the observations (solid orange line).

with returns smaller than $14 \mathrm{dBZ}$ are not considered during the comparison procedure (Toyoshima et al., 2015), and only periods when both radar coincidently detect significant precipitation are used to perform calibration. For the analysis period, a total of three GPM overpasses with significant precipitation were observed for a total number of 1516 data points for the comparison.

An example of concurrent XSAPR2 and GPM-DPR radar reflectivity observations are shown in Fig. 4a and c, respectively. The example shows that both radar detected several shallow precipitation cells with cloud top heights between 3 and $4 \mathrm{~km}$ (Fig. 4b). Beyond agreeing in the location of these precipitation echoes, both radar systems (XSAPR2 and GPM-DPR) are found to agree on their reflectivity intensity. To confirm their agreement, we estimated the contour of frequency by altitude diagram (CFAD) of the differences in radar reflectivities between the matched XSAPR2 and GPMDPR for all 1516 available observations (Fig. 4b). Above the height at which GPM-DPR is known to suffer from surface echo contamination (i.e., $1.5 \mathrm{~km}$ ), the comparison between XSAPR2 reflectivities and GPM-DPR reflectivities shows no noticeable difference (i.e., no bias). A scatter plot between the matched GPM-DPR and XSAPR2 radar reflectivity for heights above $1.5 \mathrm{~km}$ confirms the overall lack of bias beyond the expected $1 \mathrm{~dB}$ between the two radar at all reflectivities (Fig. 4d, in which the orange line depicts the best fit to the data, the dashed line represents a perfect match between the datasets and the grey shading indicates the data density). As mentioned above, scatter is expected because of the differences in configuration of both radar systems. The cloud types present in the cases available could further enhance the impact of the radar system differences, since the shallow clouds observed during the three overpasses are of similar or even smaller size compared to the GPM-DPR footprint. Small clouds could lead to nonuniform beam filling issues and as such also lead to the GPM-DPR underestimating the reflectivity of these cloud systems, which could partially explain the seemingly "high" bias of the XSAPR2 in Fig. 4d. Knowing that the ARM engineering team had calibrated the XSAPR2 just before the observations used here were collected and because this comparison with the GPM-DPR showed no bias larger than several $\mathrm{dB}$, we conclude that, for the observation period between 10 January to 1 April 2018, the XSAPR2 was reasonably well calibrated and does not require any radar reflectivity adjustments.

\section{Radar reflectivity-based precipitation rate retrievals}

\subsection{KAZR2}

In their removal techniques, Intrieri et al. (1993) and later O'Connor et al. (2005) proposed constraining water drop size distribution using lidar backscatter (related to water drop cross section) and radar Doppler spectral width (related to 

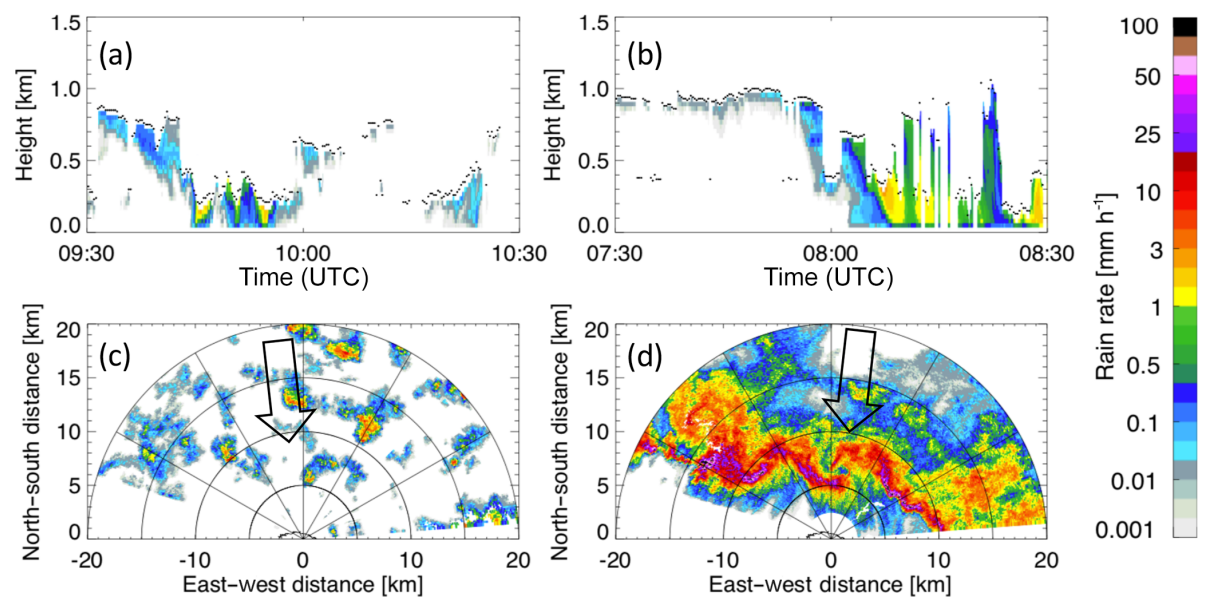

Figure 5. Retrieval of popcorn convection precipitation rate on 2 February 2018 using (a) KAZR2 (zenith between 09:30 to 10:30 UTC) and (c) KaSACR2 ( $1^{\circ}$ elevation PPI at 10:00 UTC). Retrieval of squall line precipitation rate on 2 March 2018 using (b) KAZR2 (zenith between 07:30 to 08:30 UTC) and (d) KaSACR2 ( $1^{\circ}$ elevation PPI at 08:00 UTC). Also indicated are the location of cloud bases (black dots in panels a-b) and the general wind direction (arrows in panels $\mathbf{c}-\mathbf{d}$ ). Note that KAZR2 is located at $0 \mathrm{~km}$ north-south and east-west.

the width of the water drop size distribution). This radarlidar technique can be used to estimate precipitation rate at all levels in the subcloud layer when colocated radar and ceilometer observations are available. We apply this technique to the vertically pointing ceilometer lidar and KAZR2 pair operating at the ENA. The O'Connor et al. (2005) technique requires ceilometer backscatter to be calibrated and remapped to the radar spatiotemporal resolution (here $2 \mathrm{~s} \times 30 \mathrm{~m}$ ). Ceilometer backscatter is calibrated following a variation of the O'Connor et al. (2004) technique by scaling observed path-integrated backscatter in thick stratocumulus to match theoretical cloud lidar ratio values. Satisfactory conditions for ceilometer backscatter calibration are identified as the first (in time) 20 min periods each day with a standard deviation of lidar ratio smaller than 1.5. The observed backscatter during the "satisfactory 20 min period" are input to Hogan (2006)'s multi-scattered model to determine a daily backscatter calibration factor. For days where satisfactory conditions are not observed, a climatological calibration factor of 1.35 is used to calibrate the observed backscatter. For the current analysis period, the ceilometer backscatter calibration constant was estimated to vary by around $1.35 \pm 0.08$ (Fig. 2b). Calibrated ceilometer backscatter is subsequently mapped on the KAZR2 time-height grid using a nearest neighbor approach.

This radar-lidar technique generates time-height maps of precipitation rate from $200 \mathrm{~m}$ above ground level to $90 \mathrm{~m}$ below cloud base height that are filtered for aerosol contamination. We use the clear-sky - according to KAZR2 - calibrated lidar backscatter signals as a reference for aerosol behavior. Lidar-calibrated backscatter values below the mean clearsky calibrated backscatter value at each height, depicted as the black vertical line in Fig. 2c, are systematically removed from the analysis to leave only drizzle signals. In addition to aerosol-contaminated returns, unphysical values with a median diameter smaller than $10 \mu \mathrm{m}$ or equal to or larger than $1000 \mu \mathrm{m}$ are also removed from our analysis.

Two $1 \mathrm{~h}$ examples of cloud location (black dots) and precipitation rate estimated using this technique are shown in Fig. 5a and b. Because of evaporation, the most intense precipitation rates are observed near cloud base height and a significant fraction of the precipitation does not reach the surface and falls as virga.

\subsection{XSAPR2}

As previously mentioned, the estimation of the precipitation rate for the XSAPR2 (i) cannot depend on the use of polarimetric observations because of the absence of polarimetric signature from spherical drizzle drops and (ii) cannot depend on the use of disdrometer-based estimates of the relationship between the radar reflectivity $(Z)$ and the precipitation rate $(R)$ because observations collected at the surface may not be representative of other levels in the subcloud layer, especially at the ENA where evaporation is an active process.

To accommodate changes in drizzle drop size distribution with height, which could be associated, for example, with changes in aerosol loading or evaporation, we propose constructing adaptive (both with time and height) $Z-R$ relationships in the form $Z=\alpha R^{\beta}$ from precipitation rates retrieved through the KAZR-ceilometer technique (see Sect. 4.1). Every $30 \mathrm{~min}$, independently for every level in the subcloud layer, retrieved zenith precipitation rates $\left(R\right.$ in $\left.\mathrm{mm} \mathrm{h}^{-1}\right)$ and calibrated KAZR2 reflectivity $\left(Z\right.$ in $\mathrm{mm}^{6} \mathrm{~m}^{-3}$ ) reported during a $12 \mathrm{~h}$ window around that time are related through the following relationship:

$\log _{10}(Z)=\log _{10}(\alpha)+\beta \cdot \log _{10}(R)$. 

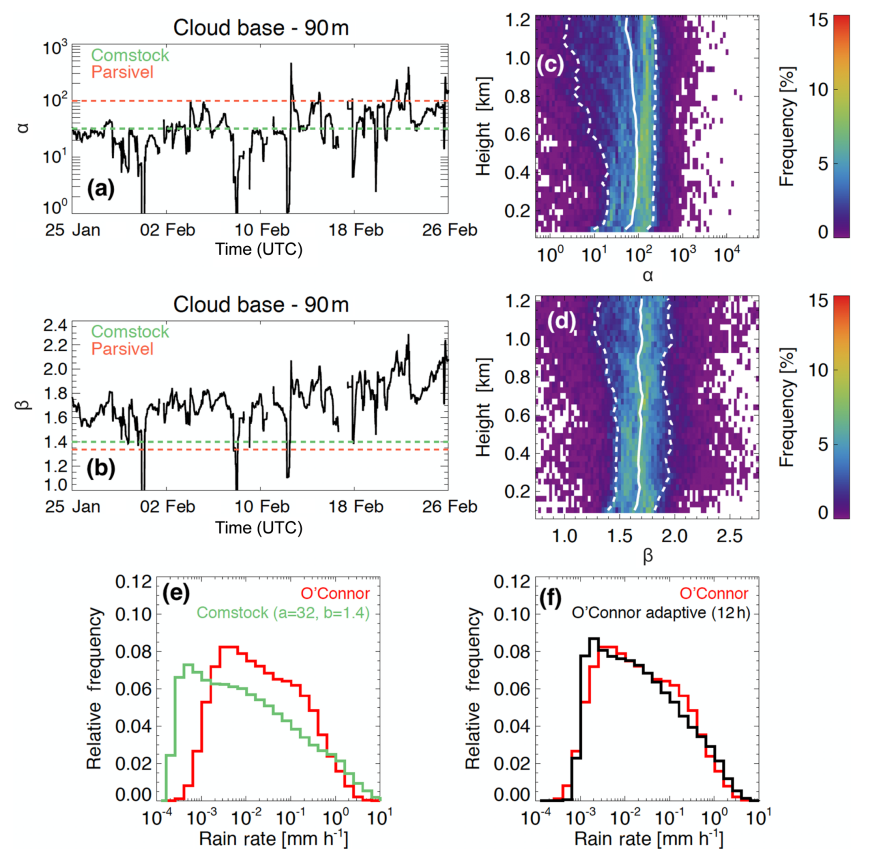

Figure 6. Time series of the $\alpha$ (a) and $\beta$ (b) coefficients used to estimate precipitation rate $90 \mathrm{~m}$ below cloud base height for a $30 \mathrm{~d}$ period that overlaps with the second phase of the ACE-ENA field campaign. For the same time period, distribution of the $\alpha$ (c) and $\beta$ (d) coefficients with height, along with their median (solid line) and 25 th and 75 th percentile values (dashed line). Precipitation rate distributions retrieved using the O'Connor et al. (2005) technique (red) and estimated using the adaptive coefficients (f, black) or the fixed coefficients proposed by Comstock et al. (2004) (e, green). Comstock et al. (2004) coefficients and coefficients determined from disdrometer observations are both presented in panels (a) and (b) using dashed green lines and dashed orange lines, respectively.

The prefactor $\alpha$ and exponent $\beta$ are estimated using a total least-squares-regression technique only considering $R$ between $10^{-3.5}$ and $10^{0.5} \mathrm{~mm} \mathrm{~h}^{-1}$ and only if at least 350 precipitation detections are available. When too few observations are available, average (for the period of the current study) $\alpha$ and $\beta$ are used. A $12 \mathrm{~h}$ time window was determined to be the best compromise between data density and the least change in water drop size distribution characteristics.

To evaluate the adaptive $Z-R$, we apply three different precipitation retrieval techniques to KAZR2 reflectivity observations: we compare precipitation rate statistics retrieved following the O'Connor et al. (2005) technique (ideal technique, red), to those estimated using $Z-R$ relationships constructed using fixed (approach proposed by Comstock et al., 2004, green) or adaptive (approach proposed here, black) coefficients (presented in Fig. 6e and f respectively). Figure $6 f$ shows that the proposed adaptive $Z-R$ relationships can reproduce the precipitation rate statistics obtained using the ideal O'Connor et al. (2005) technique. The same cannot be said from using traditional fixed $Z-R$ relationships such as
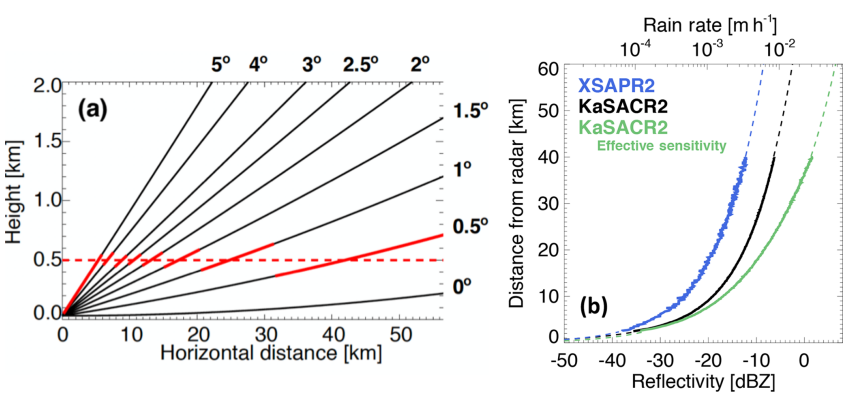

Figure 7. (a) PPI scan geometry and (b) theoretical sensitivity of the XSAPR2 (blue) and KaSACR2 (black), along with the KaSACR2 "effective" sensitivity, considering it is affected by gas attenuation (green).

that proposed by Comstock et al. (2004), which tends to create an underestimation of precipitation intensity (Fig. 6e).

Figure 6a and $\mathrm{b}$, respectively, present time series of $\alpha$ and $\beta$ near cloud base (i.e., $90 \mathrm{~m}$ below cloud base height) for a $30 \mathrm{~d}$ period that overlaps with the second phase of the ACEENA field campaign. Again, for comparison we illustrate our adaptive coefficients (black), the Comstock et al. (2004) constant coefficients (dashed green) and coefficients estimated from surface-based Parsivel laser disdrometer measurements (dashed orange). The gradual increase in both the adaptive $\alpha$ and $\beta$ coefficients over time is consistent with reports of observed conditions indicating a transition from shallow precipitation at the end of January to deep frontal precipitation at the end of February. CFADs of $\alpha$ and $\beta$ (Fig. 6c and d, respectively) show how the adaptive $\alpha$ additionally has a tendency to increase with distance from cloud base (from top to bottom), which is consistent with the evaporation of small drops that leads to an increase in mean drop size and has been previously reported by Comstock et al. (2004) and discussed in VanZanten et al. (2005).

Figure $5 \mathrm{c}$ and $\mathrm{d}$ show how, by applying the adaptive $Z-R$, XSAPR2 reflectivity observations collected at $1^{\circ}$ elevation can be converted to precipitation rate. Note how the adaptive $Z-R$ relationships were directly applied to clutter-filtered calibrated XSAPR2 radar reflectivity measurements since we estimate that, for the majority of the conditions occurring at the ENA observatory, both two-way gas attenuation and liquid attenuation at the $\mathrm{X}$ band are negligible. According to Rosenkranz (1998), at X-band frequency, gas attenuation generally amounts to $0.03 \mathrm{~dB} \mathrm{~km}^{-1}$, which is much smaller than even the radar calibration uncertainty. Similarly, Matrosov et al. (2005) discusses how, for rain rates of $2 \mathrm{~mm} \mathrm{~h}^{-1}$, liquid attenuation roughly amounts to $0.015 \mathrm{~dB} \mathrm{~km}^{-1}$, which over the depth of the shallow systems producing this type of precipitation cumulates to liquid attenuation less than $1 \mathrm{~dB}$, again within the radar calibration uncertainty. We do, however, acknowledge that, for deep convective systems, liquid attenuation correction would be granted, but since this type of precipitating system was not being frequently observed at 


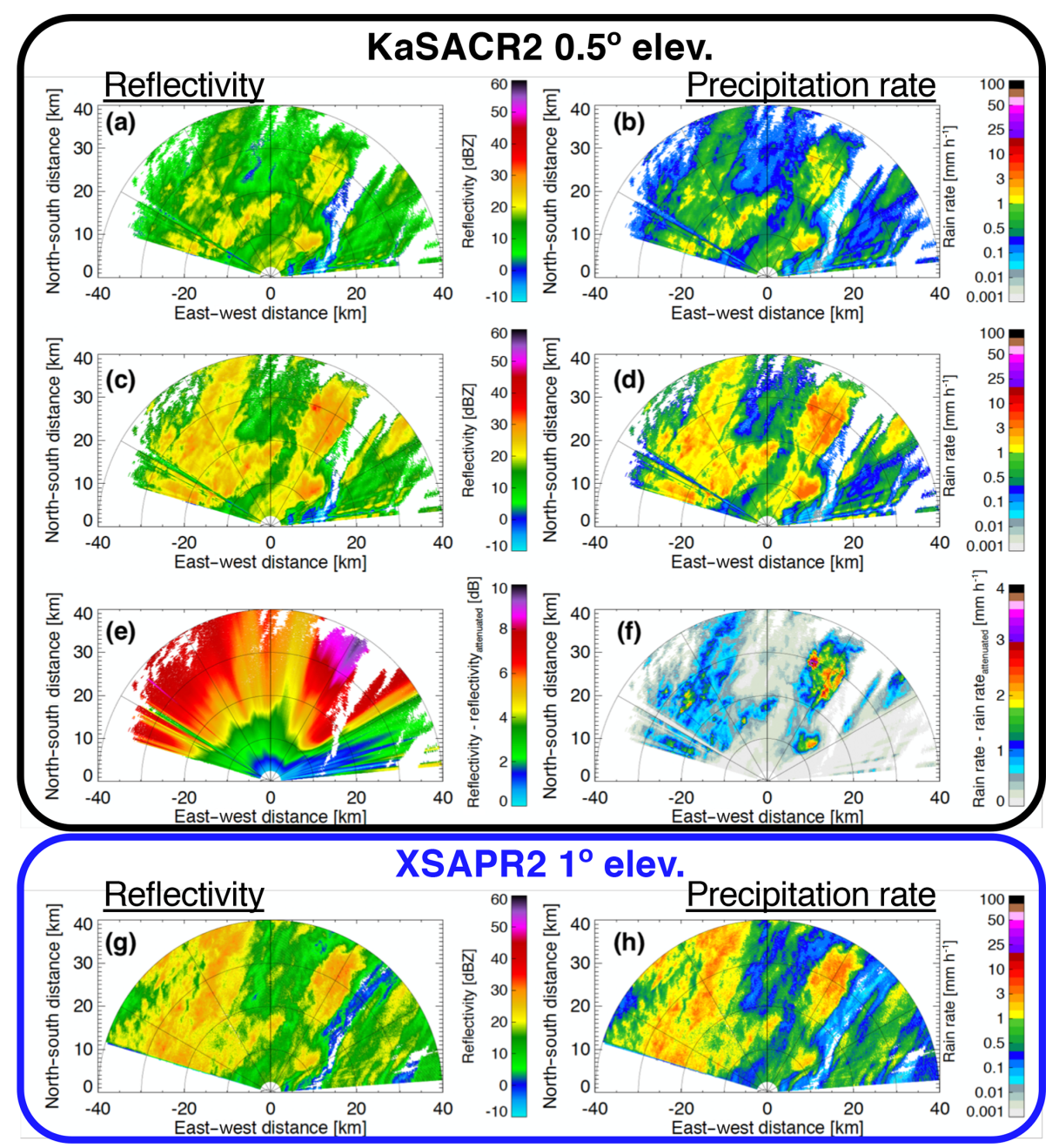

Figure 8. Example of observations and retrievals of the conditions on 13 February 2018 at 00:10 UTC. Shown for the KaSACR2 when performing $0.5^{\circ}$ elevation PPI are (a) the radar reflectivity field, corrected for gaseous attenuation and neglecting liquid water attenuation, and (b) the corresponding precipitation rate retrieved using adaptive $Z-R$ relationships; (c) the radar reflectivity field, corrected for both gas and liquid water attenuation and (d) corresponding precipitation rate; and (e) the difference between (a) and (c), showing the rangeaccumulated radar reflectivity, liquid water attenuation correction, and (f) the corresponding precipitation rate bias. The bottom panels (g) and (h) show simultaneously collected XSAPR2 $1.0^{\circ}$ PPI observations for reference.

the ENA observatory, we did not apply any liquid attenuation correction to the XSAPR2 measurements.

\subsection{KaSACR2}

Before quantitatively estimating precipitation rate from KaSACR radar reflectivity measurements, we also consider how its wavelength responds to the presence of atmospheric gases. The Rosenkranz (1998) propagation model suggests that, for the conditions observed at the ENA, two-way gas attenuation of Ka-band signals can amount to $0.25 \mathrm{~dB} \mathrm{~km}^{-1}$. Although this may seem small and can be insignificant when collecting observations of boundary layer clouds in profiling mode, in scan mode attenuation of Ka-band reflectivity by atmospheric gas can amount to $10 \mathrm{~dB}$ at $40 \mathrm{~km}$ range
(Fig. $7 \mathrm{~b}$ difference between the black and green curve) and as such should not be neglected. Also note that in addition to the gaseous attenuation, Ka-band radar suffer from considerable liquid water attenuation. According to Matrosov (2005), the relationship between one-way liquid attenuation $a\left(\mathrm{~dB} \mathrm{~km}^{-1}\right)$ and precipitation rate $R\left(\mathrm{~mm} \mathrm{~h}^{-1}\right)$ is very robust $(a=0.28 R)$. His findings were verified using Mie scattering calculations on all particle size distributions observed by the ENA Parsivel laser disdrometer. Figure $8 \mathrm{a}$ and $\mathrm{b}$ illustrate an example of observations collected by the KaSACR at 0.5 elevation on 13 February 2018. In this example, liquid contributed anywhere from 2 to $10 \mathrm{~dB}$ in total attenuation at the Ka-band frequency over the $40 \mathrm{~km}$ observation domain (Fig. 8e). If left uncorrected, liquid attenuation can lead to errors in precipitation rate estimates 
up to $3 \mathrm{~mm} \mathrm{~h}^{-1}$ in this example (Fig. $8 \mathrm{f}$ ). Figure $8 \mathrm{~g}$ and $\mathrm{h}$ also show reflectivity and precipitation rate for the XSAPR2 which, as discussed in the previous section, only suffers from negligible attenuation. With the caveat that we are comparing rain rates retrieved at slightly different slanted elevations, comparing rain rates retrieved from the XSAPR2 observations (Fig. 8h) and from the KaSACR2 observations corrected for both gas and liquid attenuation (Fig. 8d) also highlights the fact that even after all corrections are performed, the KaSACR2 "realized" sensitivity does not allow it to detect some of the precipitation the more sensitive XSAPR2 can detect. The range-dependent sensitivity of both sensors can be contrasted in Fig. $7 b$.

\section{Radar systems complementarity}

As discussed in Sect. 2, the KAZR2, KaSACR2 and XSAPR2 radar sample light precipitation using very different transmission and sampling strategies. In this section we highlight some of the advantages and tradeoffs of using each radar system to characterize different aspects of light precipitation variability.

First, this is done by contrasting the two scanning radar XSAPR2 and KaSACR2. Although the Ka-band SACR2 experiences less sea clutter than the X-band SAPR2, it has a coarser temporal resolution; the KaSACR2 only currently performs one PPI scan at $0.5^{\circ}$ every $15 \mathrm{~min}$ because it also performs other scan strategies for cloud sampling. In addition, based on their technical specifications (Table 1), the XSAPR2 single pulse radar sensitivity is approximately $10 \mathrm{~dB}$ higher than that of the KaSACR2 (Fig. 7b blue and black line, respectively). Finally, the Ka-band SACR2 also suffer from significantly more attenuation from atmospheric gases (Fig. 7b green line) and liquid water, which even if corrected for still decreases its "realized" sensitivity. For all these reasons, we conclude that the XSAPR2 is more suitable for characterizing light precipitation variability over large domains.

Second, to contrast the XSAPR2 and KAZR2, we compare, over the course of $36 \mathrm{~h}$ between 00:00 UTC, 2 February, and 12:00UTC, 3 February, hourly precipitation rate variability in the forms of frequency of occurrence in different precipitation rate bins (pdfs). Figure 9a shows estimates from the scanning XSAPR2 collecting observation in PPI mode covering a domain between 2.5 and $40 \mathrm{~km}$ at $1^{\circ}$ elevation thus transecting heights between $\sim 100$ and $750 \mathrm{~m}$ (also refer to Fig. 7a to visualize the XSAPR2 sampling geometry). Figure $9 b$ and $c$, respectively, show estimates from the vertically pointing KAZR2 $200 \mathrm{~m}$ above the surface and $90 \mathrm{~m}$ below cloud base, which was around $850 \mathrm{~m}$.

From Fig. 9b and c, it is evident that KAZR2, with its high sensitivity, is especially well suited to document light precipitation and drizzle falling at a rate as low as $10^{-4} \mathrm{~mm} \mathrm{~h}^{-1}$. KAZR2 observations show a reduction in the number of precipitation events and in precipitation intensity from cloud base (Fig. 9c) towards the surface (Fig. 9b). This supports the previous hypothesis that at the ENA a large fraction of the light precipitation falls in the form of virga (Ahlgrimm and Forbes, 2014; Yang et al., 2018). Under these circumstances, where the character of precipitation changes dramatically with height and its intensity is very low (below $10^{-3} \mathrm{~mm} \mathrm{~h}^{-1}$ ), scanning radar observation at a fixed elevation may become inadequate to characterize surface precipitation over a large domain owing to the Earth's curvature effects. Figure $7 \mathrm{a}$ illustrates the height above the surface of a $1^{\circ}$ elevation scan with distance away from the radar; at a distance of $10-20 \mathrm{~km}$ the radar beam is already $250 \mathrm{~m}$ above the surface while at a distance of $20-30 \mathrm{~km}$ this same radar beam is now $500 \mathrm{~m}$ from the surface. This nonuniformity of the radar beam height with distance makes scanning cloud radar observations at one elevation angle more adequate to document the character of vertically uniform precipitation. The rapid sampling rate of the KAZR2 also allows it to describe the vertical structure of precipitation variability at a high temporal scale (as short as $2 \mathrm{~s}$ ).

On the other hand, one drawback of vertically pointing KAZR2 observations is that they are limited to sampling only those precipitation events advected overhead. It is not uncommon to temporally average vertically pointing observation to create a proxy for domain-averaged statistics; however, as depicted in Fig. 5, it may be difficult to address the domain representativeness of $1 \mathrm{~h}$ of vertically pointing precipitation rate estimates. It can also be challenging to interpret the mesoscale organization of the precipitation field using vertically pointing observations alone. Scanning systems such as the XSAPR2 can help fill this gap. Figure 5c and d show XSAPR2 $1^{\circ}$ elevation PPI scans collected at 10:00 and 08:00 UTC, respectively, which corresponds to the center time of the KAZR2 time-height observations presented in Fig. 5a and b. XSAPR2 can observe the structure and scales of popcorn precipitation and squall line precipitation over a domain of roughly $2500 \mathrm{~km}^{2}$. In its current configuration, the XSAPR2 system can be used to document the horizontal structure and temporal variability of light-tomoderate precipitation on scales of $\sim 5 \mathrm{~min}$. Referring back to Fig. 9a, looking at the hourly precipitation rate pdfs it is evident that by covering a larger domain XSAPR2 is able to observe a larger number of near surface sporadic precipitation events such as that observed on 3 February around 00:00 and of isolated deep convective events responsible for more intense precipitation $\left(R>3 \mathrm{~mm} \mathrm{~h}^{-1}\right)$ such as that observed on 3 February around 08:00.

\section{Gridded domain precipitation rate estimation}

One way for scanning radar systems to overcome some of the limitations of their scanning strategy is to develop horizontal, two-dimensional, gridded maps of the radar observables and other quantities (i.e., precipitation rate) using measurements 


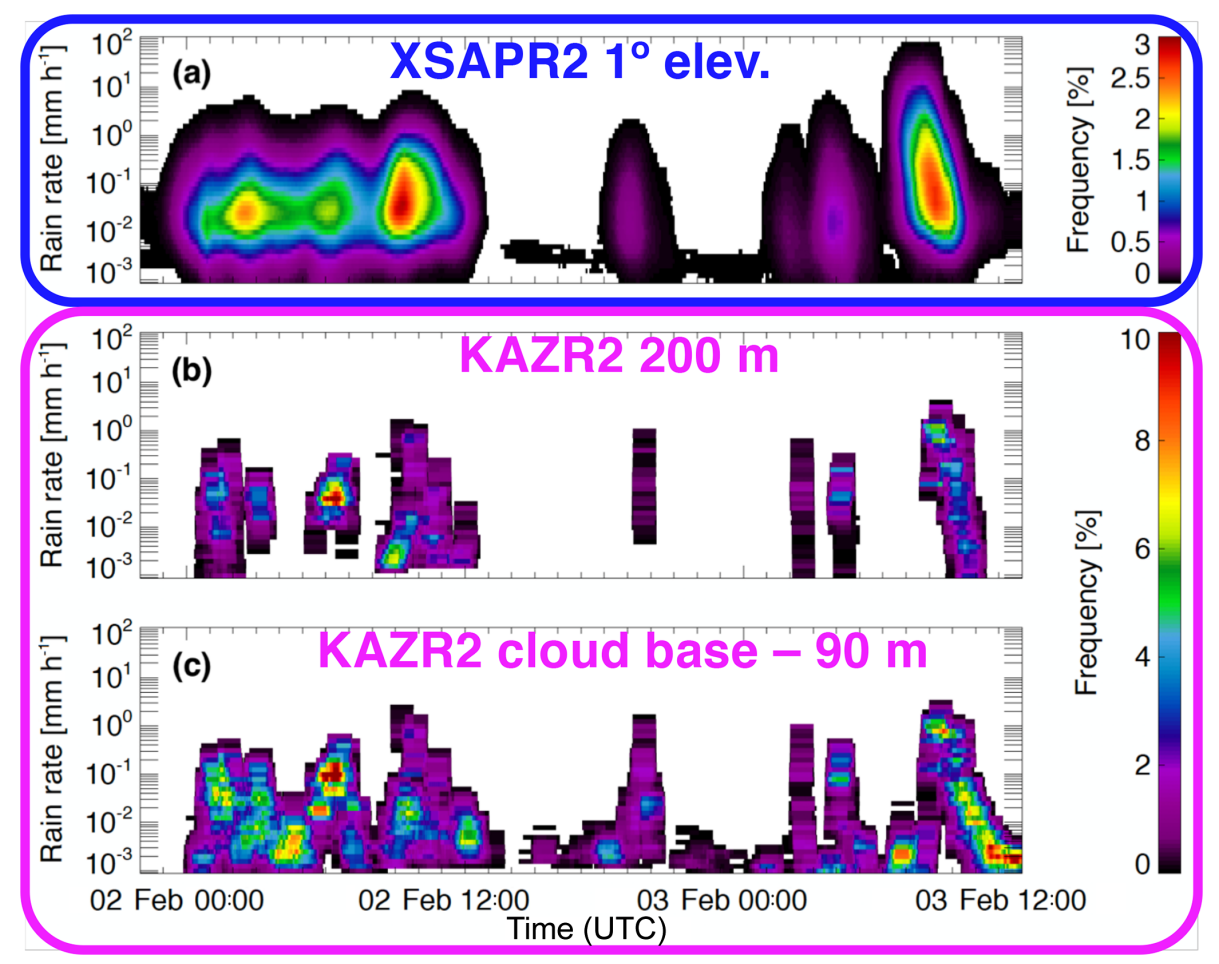

Figure 9. For a $36 \mathrm{~h}$ period (00:00 UTC, 2 February, to 12:00 UTC, 3 February), hourly probability density functions (pdfs) of precipitation rate are presented, estimated from (a) XSARP2 when performing a $1^{\circ}$ elevation PPI scan, (b) KAZR2 $200 \mathrm{~m}$ from the surface, and (c) KAZR2 $90 \mathrm{~m}$ below cloud base height.

collected at different elevation angles (i.e., construct constant altitude plan position indicator, CAPPI, maps). Here, gridded XSAPR2 CAPPI maps are constructed as follows: we perform the polar to Cartesian transformation for each individual reflectivity measurement using a standard atmosphere radio propagation model that considers the height of the beam above the Earth's surface and the distance between the radar and the projection of the beam along the Earth's surface (Doviak and Zrnic, 1993). Using these Cartesian coordinates each PPI is mapped on a $100 \mathrm{~m}$ horizontal grid in which each grid point is populated using a triangulation technique (i.e., the nearest three observations are linearly interpolated to populate the grid cell). Then, every $100 \mathrm{~m}$ in the horizontal, a grid point at constant altitude is populated by (i) a measured value if falling on an elevation where observations were collected or (ii) a weighted average of the gridded data from the three closest PPI. The weight being the inverse horizontal distance from the grid location. The aforementioned adaptive $Z-R$ relationships are then applied to the Cartesian grid reflectivity observations to produce precipitation rate CAPPI. Note that producing an unbiased assessment of precipitation rate over the domain covered by the scanning radar would require the application of a uniform sensitivity threshold over the entire domain. The need for such a threshold creates a tradeoff between documenting a large domain and documenting weak precipitation events. As quantified in
Fig. 7b, at a distance of $40 \mathrm{~km}$ the XSAPR2 is only capable of detecting precipitation events of an intensity larger than $10^{-2.8} \mathrm{~mm} \mathrm{~h}^{-1}$ and any desire to document weaker precipitation rate events would further limit domain size.

\section{Domain-averaged precipitation rate - when do temporal and horizontal precipitation variability converge?}

The addition of the XSAPR2 at the ENA observatory offers new insights into precipitation variability and organization over a domain of 40-60 km radius around the size. However, the XSAPR2 data record is not as long as the KAZR2 data record, which now spans 5 years at the ENA, totaling up to 7.5 years if we consider the Cloud, Aerosols and Precipitation in the Marine Boundary Layer (CAP-MBL) campaign that took place at the site from April 2009 to January 2011 (Wood et al., 2015). Because of their longer data record, profiling radar observations have the potential to inform us about decadal precipitation variability both temporal and structural. However, with vertically pointing observations, it is near impossible to disentangle temporal evolution from horizontal structure. Classical approaches rely on the Taylor hypothesis of frozen turbulence to convert elapsed time to horizontal dimension using the horizontal wind speed responsible for advecting cloud and precipitation overhead. While widely used, 


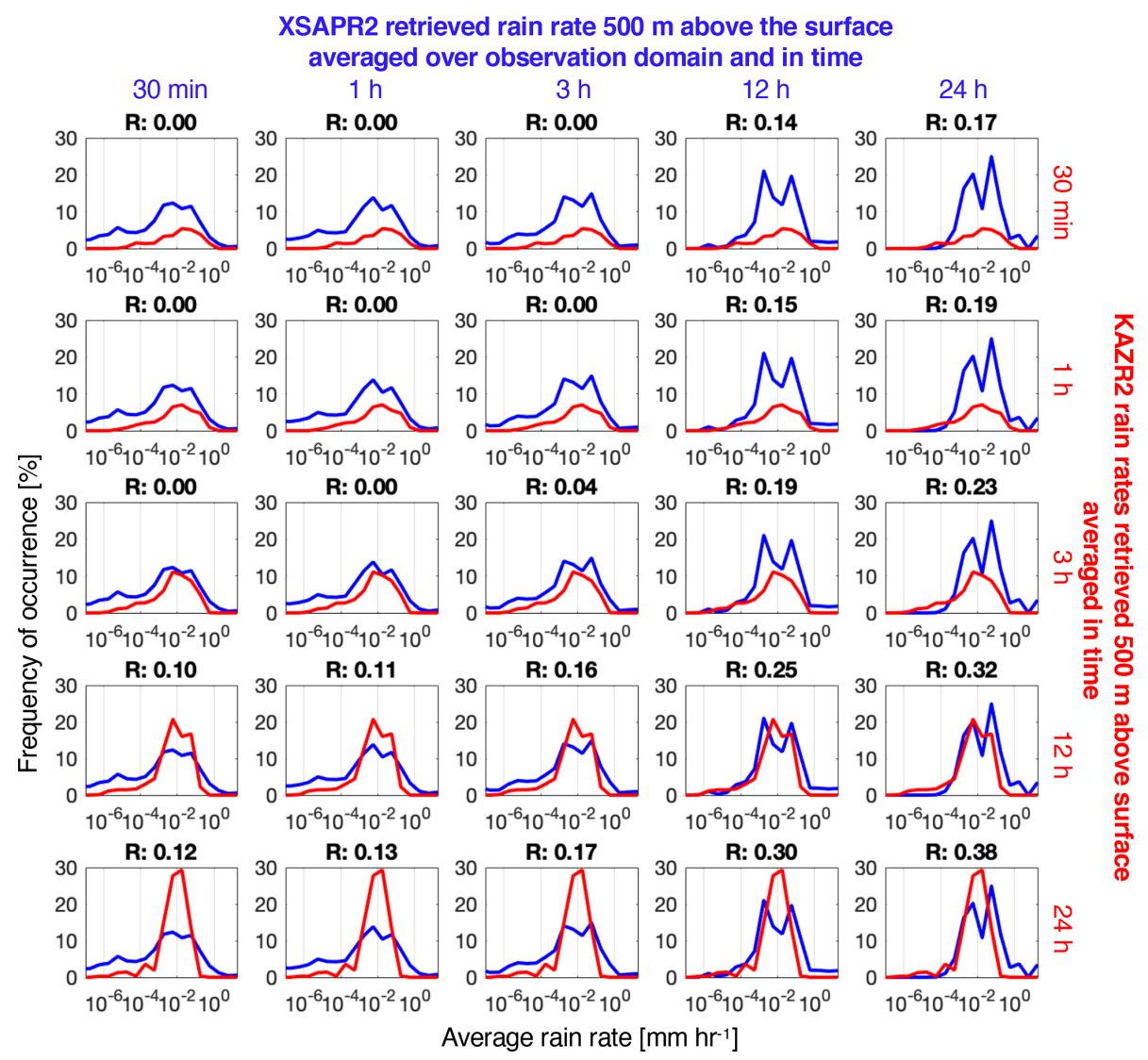

Figure 10. Probability density function of average (over different time windows) precipitation rate as estimated the XSAPR2 and by the KAZR2 (red), both at $500 \mathrm{~m}$ above the surface in $10^{0.5} \mathrm{~mm} \mathrm{~h}^{-1}$ bins. The XSAPR2 precipitation rates $500 \mathrm{~m}$ above the surface being from gridded CAPPI constructed using a collection of PPI scans and limited to the domain between 2.5 and $40 \mathrm{~km}$ around the location of the KAZR2. Over each box is the correlation coefficient $(R)$ between the XSAPR2 and the KAZR2 average precipitation rates.

little research has been conducted to determine the validity and limitations of this assumption (see Oue et al., 2016 for a discussion on cloud fraction). In this section we seek to determine how long one needs to observe precipitation advected overhead to gather statistical precipitation information equivalent to that of a $40 \mathrm{~km}$ radius domain.

Over the 3-month period between 10 January and 1 April 2018, the domain representativeness of KAZR2 precipitation rate estimates is evaluated using XSAPR2 observations collected over a domain of $40 \mathrm{~km}$ radius around the site. Although any height could be used, we perform this comparison at the specific height of $500 \mathrm{~m}$. While KAZR2 precipitation retrievals can be directly extracted at $500 \mathrm{~m}$, those from XSAPR2 must be extracted from gridded CAPPI fields that are constructed following the details provided in Sect. 6 using a collection of PPI scans. To remove any bias caused by variations in minimum performance of both sensors, a minimum precipitation rate threshold of $10^{-2.8} \mathrm{~mm} \mathrm{~h}^{-1}$ is applied to both sensors reflecting the detectability of the XSAPR2 over the selected domain. Statistics for both sensors are estimated using different set averaging time intervals (30 min, $1 \mathrm{~h}, 3 \mathrm{~h}, 12 \mathrm{~h}$ and $24 \mathrm{~h}$ ), which allows us to monitor the tem- poral variability of domain-averaged precipitation rate. For XSAPR2, using a sliding window, we average all 5 min PPI observations collected during the chosen time interval. For KAZR2, we center the time window on the XSAPR2 estimates and average all $2 \mathrm{~s}$ observations collected during the chosen time interval.

Figure 10 shows the precipitation rate pdfs estimated from the XSAPR2 (blue) and KAZR2 (red) for varying averaging time intervals. Focusing on features such as the width, the minimum, maximum, and modes of the precipitation rate statistical distribution, results indicate that neither $30 \mathrm{~min}$ nor $1 \mathrm{~h}$ averaging of KAZR2 precipitation rate estimates can be used to replicate the precipitation rate statistics corresponding to those of the domain averaged over $30 \mathrm{~min}$ (Fig. 10, left column). Averaging of $3 \mathrm{~h}$ of KAZR2 data improves the representativeness of the domain-averaged rain rate variabilities on scales of 1 to $3 \mathrm{~h}$ (third row, second and third columns). Convergence between XSAPR2 and KAZR2 timeaveraged precipitation rate estimates is seemingly best when considering the variability of domain-averaged precipitation rate over $12 \mathrm{~h}$ (correlation coefficient $R=0.25$ ) or longer timescales. The $12 \mathrm{~h}$ average domain-averaged precipitation 
rate pdf from XSAPR2 and $12 \mathrm{~h}$ average precipitation rate pdf from KAZR2 are similar in both magnitude and mode location.

Although these results are estimated with few observational cases (3-month period), they clearly suggest that XSAPR2 observations are necessary to characterize short-term $(<1 \mathrm{~h})$ domain-averaged precipitation rate characteristics. They also suggest that longer-term $(12 \mathrm{~h})$ domain-averaged precipitation rate characteristics can be estimated by averaging either XSAPR2 or KAZR2 observations using time windows of similar lengths.

\section{Summary and conclusions}

The ARM ENA observatory is the first island-based climate research facility equipped with colocated radar and lidar capable of sampling light oceanic precipitation. Here we presented the characteristics and first light observations from three state-of-the-art second-generation radar systems: the Ka-band zenith radar (KAZR2), the Ka-band scanning ARM cloud radar (KaSACR2) and the X-band scanning ARM precipitation radar (XSAPR2).

One of the initial concerns of operating scanning cloud and precipitation radar over the ocean is the impact of sea clutter, especially at low elevation angles. Nearly $100 \mathrm{~h}$ of clear sky observations were used to characterize the properties of sea clutter in KaSACR2 and XSAPR2 observations. Analysis of clear and cloudy-sky periods and intercomparison of the meteorological and non-meteorological echoes of the KaSACR2 made it possible to design a relatively simple filtering technique to isolate precipitation echoes in XSAPR2 observations. In short, a threshold on normalized coherent power $(<0.3)$ and on average $(5 \times 5$ window $)$ crosscorrelation $(<0.55)$ can mitigate second-trip echoes and seaclutter echoes. Everything considered, we find that XSAPR2 observations collected at $1^{\circ}$ elevation, albeit suffering from more clutter contamination than KaSACR2, offer the best compromise between clutter contamination and proximity to the surface.

Measurement calibration is also essential to quantitative precipitation rate retrieval. We applied the Kollias et al. (2019) technique to calibrate the KAZR2 radar reflectivity measurements using Parsivel disdrometer and CloudSat observations. Because they were found to match, the same offset is applied to the KaSACR2 observations. To confirm the recent calibration performed by the ARM engineering team and to explore alternative calibration methods, the XSAPR2 reflectivity measurements were statistically compared to GPM Ku-band radar observations collected around the ENA site. The analysis indicated no noticeable offset; thus, no calibration offset was applied to the XSAPR2. These techniques could be used in the future as a supplement to the ARM radar engineering group efforts to characterize the ENA radar's reflectivity measurements.
We capitalized on the availability of closely collected (in both time and physical distance) KAZR2, ceilometer lidar and XSAPR2 measurements to estimate precipitation rate. Precipitation rates retrieved using the O'Connor et al. (2005) radar-lidar technique have the advantage of being estimated with fewer assumptions on the drizzle drop size distribution and can accommodate changes in aerosol loading, liquid water path and evaporation. Unfortunately, due to a lack of scanning lidar observations, we cannot apply this technique to scanning radar observations. Instead, we showed how relating the retrieved precipitation rates in the column to radar reflectivity can be used to estimate adaptive (in both time and height) parameters that related observed radar reflectivity $(Z)$ to precipitation rate $(R)$ in the form $Z=\alpha R^{\beta}$. These adaptive parameters can then be applied to retrieve precipitation rate over the domain covered by scanning cloud radar systems. We report these adaptive parameters for the period between 10 January and 1 April 2018, which includes the second phase of the ACE-ENA campaign. These adaptive parameters were shown to capture changes in drop size distribution with height as well as temporal changes in the cloud field.

Throughout this work, comparison of precipitation rate statistics estimated by all three sensors highlighted the following:

1. Because of strong signal attenuation by gases and liquid at the Ka band, X-band radar systems are more suited for precipitation mapping, especially over large domains.

2. When the character of precipitation varies rapidly with height, for instance owing to an active evaporation process, zenith-pointing radar systems are more suited for precipitation characterization.

3. However, zenith-pointing observations collected over periods shorter than $12 \mathrm{~h}$ should not be considered representative of a domain, especially one as large as $2500 \mathrm{~km}^{2}$ (i.e., $\sim 40 \mathrm{~km}$ radius half circle).

4. When it comes to capturing the general shape of the precipitation rate distribution, $12 \mathrm{~h}$ of zenith-pointing radar observations can be averaged to represent the $12 \mathrm{~h}$ variability of a $\sim 40 \mathrm{~km}$ radius half circle domain.

5. Shorter-term domain precipitation rate variability can only be captured by scanning precipitation radar systems, in particular those operating at weakly attenuating frequencies and with high sensitivity, such as the XSAPR2.

6. Scanning sensors such as the XSAPR2 are also better suited to documenting sporadic and horizontal homogeneous precipitation including precipitation presenting mesoscale organization. 
In a nutshell, the considerable differences in precipitation rate statistics estimated by the XSAPR2 and KAZR2 challenge our ability to objectively estimate precipitation rate statistics over a domain for applications such as the evaluation of high temporal resolution model output. Factors such as instrument sensitivity, sampling resolution, sampling height and domain size should always be considered when comparing model output to observations. One way to consider these factors could be to convert model output rain rates to observable rain rate through the use of forward simulators, which can use drop size and atmospheric conditions information to reproduce the attenuation affecting radar signals. Several forward simulators further take into consideration the dependency of radar sensitivity with range, which dictates the minimum detectable rain rate at various distances within a domain (e.g., Tatarevic et al., 2015; Lamer et al., 2018).

Data availability. Ground-based data were obtained from the Atmospheric radiation measurement (ARM) user facility, a U.S. Department of Energy (DOE) Office of Science user facility managed by the Office of Biological and Environmental Research. Spaceborne data were obtained from the National Aeronautics and Space Administration. Column rain rate retrievals were made available by the authors as an ARM PI product.

Author contributions. KL coordinated the project, performed the intercomparisons between the precipitation rates produced by the three radar systems and produced the final manuscript draft. PK supervised ZZ and BPT as they, respectively, analyzed the KAZR2 and both the KaSACR 2 and XSAPR2 observations. Analysis steps included performing data post-processing, calibration and precipitation rate retrievals. BPT also produced the CAPPI part of this work. BI and NB provided a wealth of information about the radar system characteristics as well as guidance on radar data calibration. All coauthors read the manuscript draft and contributed comments.

Competing interests. The authors declare that they have no conflict of interest.

Acknowledgements. The authors would like to thank the two anonymous reviewers and Gianfranco Vulpiani for their involvement in the review process.

Financial support. Katia Lamer's contributions were supported by subcontract 300324 of the Pennsylvania State University and the Brookhaven National Laboratory in support of the U.S. Department of Energy (DOE) ARM-Atmospheric Science Research (ASR) Radar Science group. Bernat Puigdomènech Treserras' contributions were supported through a subcontract with the Brookhaven National Laboratory in support of the ARM-ASR Radar Science group. Zeen Zhu's contributions were supported by the U.S. DOE ASR ENA Site Science award. Bradley Isom and Nitin Bharadwaj's contributions were supported by Pacific Northwest National Laboratory. Pavlos Kollias' contributions were supported by the U.S DOE under contract DE-SC0012704.

Review statement. This paper was edited by Gianfranco Vulpiani and reviewed by two anonymous referees.

\section{References}

Adler, R. F., Wang, J.-J., Gu, G., and Huffman, G. J.: A ten-year tropical rainfall climatology based on a composite of TRMM products, J. Meteorol. Soc. Jpn., 87, 281-293, 2009.

Ahlgrimm, M. and Forbes, R.: Improving the representation of low clouds and drizzle in the ECMWF model based on ARM observations from the Azores, Month. Weather Rev., 142, 668-685, 2014.

Alku, L., Moisseev, D., Aittomäki, T., and Chandrasekar, V.: Identification and suppression of nonmeteorological echoes using spectral polarimetric processing, IEEE T. Geosci. Remote, 53, 3628-3638, 2015.

Bretherton, C. S., Uttal, T., Fairall, C. W., Yuter, S. E., Weller, R. A., Baumgardner, D., Comstock, K., Wood, R., and Raga, G. B.: The EPIC 2001 stratocumulus study, B. Am. Meteorol. Soc., 85, 967-978, 2004.

Comstock, K. K., Wood, R., Yuter, S. E., and Bretherton, C. S.: Reflectivity and rain rate in and below drizzling stratocumulus, Q. J. Roy. Meteor. Soc., 130, 2891-2918, 2004.

Comstock, K. K., Bretherton, C. S., and Yuter, S. E.: Mesoscale variability and drizzle in southeast Pacific stratocumulus, J. Atmos. Sci., 62, 3792-3807, 2005.

Doviak, R. and Zrnic, D.: Doppler Radar and, Academic Press, 562 pp., 1993.

Ellis, T. D., L'Ecuyer, T., Haynes, J. M., and Stephens, G. L.: How often does it rain over the global oceans? The perspective from CloudSat, Geophys. Res. Lett., 36, https://doi.org/10.1029/2008GL036728, 2009.

Feingold, G., Koren, I., Wang, H., Xue, H., and Brewer, W. A.: Precipitation-generated oscillations in open cellular cloud fields, Nature, 466, 849-852, 2010.

Gorgucci, E., Scarchilli, G., and Chandrasekar, V.: Sensitivity of multiparameter radar rainfall algorithms, J. Geophys. Res. Atmos., 105, 2215-2223, 2000.

Gregers-Hansen, V. and Mital, R.: An empirical sea clutter model for low grazing angles, Radar Conference, 2009 IEEE, 1-5, 2009.

Hogan, R. J.: Fast approximate calculation of multiply scattered lidar returns, Appl. Optics, 45, 5984-5992, 2006.

Horst, M., Dyer, F., and Tuley, M.: Radar sea clutter model, Antennas and Propagation, 6-10, 1978.

Iguchi, T., Seto, S., Meneghini, R., Yoshida, N., Awaka, J., and Kubota, T.: GPM/DPR level-2 algorithm theoretical basis document, NASA Goddard Space Flight Center, Greenbelt, MD, USA, Tech. Rep, 2010.

Intrieri, J. M., Stephens, G. L., Eberhard, W. L., and Uttal, T.: A method for determining cirrus cloud particle sizes using lidar and radar backscatter technique, J. Appl. Meteorol., 32, 1074-1082, 1993. 
Kollias, P., Bharadwaj, N., Widener, K., Jo, I., and Johnson, K.: Scanning ARM cloud radars. Part I: Operational sampling strategies, J. Atmos. Ocean. Tech., 31, 569-582, 2014a.

Kollias, P., Jo, I., Borque, P., Tatarevic, A., Lamer, K., Bharadwaj, N., Widener, K., Johnson, K., and Clothiaux, E. E.: Scanning ARM cloud radars. Part II: Data quality control and processing, J. Atmos. Ocean. Tech., 31, 583-598, 2014b.

Kollias, P., Clothiaux, E. E., Ackerman, T. P., Albrecht, B. A., Widener, K. B., Moran, K. P., Luke, E. P., Johnson, K. L., Bharadwaj, N., and Mead, J. B.: Development and applications of ARM millimeter-wavelength cloud radars, Meteor. Mon., 57, 17.11-17.19, 2016.

Kollias, P., Puigdomènech Treserras, B., and Protat, A.: Calibration of the 2007-2017 record of ARM Cloud Radar Observations using CloudSat, Atmos. Meas. Tech. Discuss., https://doi.org/10.5194/amt-2019-34, in review, 2019.

Lamer, K., Kollias, P., and Nuijens, L.: Observations of the variability of shallow trade wind cumulus cloudiness and mass flux, J. Geophys. Res.-Atmos., 120, 6161-6178, 2015.

Lamer, K., Fridlind, A. M., Ackerman, A. S., Kollias, P., Clothiaux, E. E., and Kelley, M.: $(\mathrm{GO})^{2}$-SIM: a GCM-oriented groundobservation forward-simulator framework for objective evaluation of cloud and precipitation phase, Geosci. Model Dev., 11, 4195-4214, https://doi.org/10.5194/gmd-11-4195-2018, 2018.

Luke, E. P., Kollias, P., Johnson, K. L., and Clothiaux, E. E.: A technique for the automatic detection of insect clutter in cloud radar returns, J. Atmos. Ocean. Tech., 25, 1498-1513, 2008.

Mather, J., Turner, D., and Ackerman, T.: Scientific maturation of the ARM Program, Meteor. Mon., 57, 4.1-4.19, 2016.

Matrosov, S. Y.: Attenuation-based estimates of rainfall rates aloft with vertically pointing Ka-band radars, J. Atmos. Ocean. Tech., 22, 43-54, 2005.

Matrosov, S. Y., Kingsmill, D. E., Martner, B. E., and Ralph, F. M.: The utility of X-band polarimetric radar for quantitative estimates of rainfall parameters, J. Hydrometeorol., 6, 248-262, 2005

Miller, M. A. and Yuter, S. E.: Detection and characterization of heavy drizzle cells within subtropical marine stratocumulus using AMSR-E 89-GHz passive microwave measurements, Atmos. Meas. Tech., 6, 1-13, https://doi.org/10.5194/amt-6-12013, 2013.

Moisseev, D. N. and Chandrasekar, V.: Polarimetric spectral filter for adaptive clutter and noise suppression, J. Atmos. Ocean. Tech., 26, 215-228, 2009.

Moyer, K. A. and Young, G. S.: Observations of mesoscale cellular convection from the marine stratocumulus phase of "FIRE", Bound.-Lay. Meteorol., 71, 109-133, 1994.

Nathanson, F. E., Reilly, J. P., and Cohen, M. N.: Radar design principles-Signal processing and the Environment, NASA STI/Recon Technical Report A, 91, 1991.

Nguyen, C. M., Moisseev, D. N., and Chandrasekar, V.: A parametric time domain method for spectral moment estimation and clutter mitigation for weather radars, J. Atmos. Ocean. Tech., 25, 83-92, 2008.

O'Connor, E. J., Illingworth, A. J., and Hogan, R. J.: A technique for autocalibration of cloud lidar, J. Atmos. Ocean. Tech., 21, 777-786, 2004.
O'Connor, E. J., Hogan, R. J., and Illingworth, A. J.: Retrieving stratocumulus drizzle parameters using Doppler radar and lidar, J. Appl. Meteorol., 44, 14-27, 2005.

Oue, M., Kollias, P., North, K. W., Tatarevic, A., Endo, S., Vogelmann, A. M., and Gustafson, W. I.: Estimation of cloud fraction profile in shallow convection using a scanning cloud radar, Geophys. Res. Lett., 43, https://doi.org/10.1002/2016GL070776, 2016.

Paluch, I. and Lenschow, D.: Stratiform cloud formation in the marine boundary layer, J. Atmos. Sci., 48, 2141-2158, 1991.

Pazmany, A. L., Mead, J. B., Bluestein, H. B., Snyder, J. C., and Houser, J. B.: A mobile rapid-scanning X-band polarimetric (RaXPol) Doppler radar system, J. Atmos. Ocean. Tech., 30, 1398-1413, 2013.

Rapp, A. D., Lebsock, M., and L'Ecuyer, T.: Low cloud precipitation climatology in the southeastern Pacific marine stratocumulus region using CloudSat, Environ. Res. Lett., 8, 014027, https://doi.org/10.1088/1748-9326/8/1/014027, 2013.

Rauber, R. M., Stevens, B., Ochs III, H. T., Knight, C., Albrecht, B. A., Blyth, A., Fairall, C., Jensen, J., Lasher-Trapp, S., and MayolBracero, O.: Rain in shallow cumulus over the ocean: The RICO campaign, B. Am. Meteor. Soc., 88, 1912-1928, 2007.

Rémillard, J. and Tselioudis, G.: Cloud regime variability over the Azores and its application to climate model evaluation, J. Climate, 28, 9707-9720, 2015.

Rosenkranz, P. W.: Water vapor microwave continuum absorption: A comparison of measurements and models, Radio Sci., 33, 919928, 1998.

Ryzhkov, A., Zhang, P., Doviak, R., and Kessinger, C.: Discrimination between weather and sea clutter using Doppler and dualpolarization weather radars, Proc. 27th General Assembly of the International Union of Radio Science, 3, 2002.

Savic-Jovcic, V. and Stevens, B.: The structure and mesoscale organization of precipitating stratocumulus, J. Atmos. Sci., 65, 1587 1605, 2008.

Schumacher, C. and Houze Jr., R. A.: Comparison of radar data from the TRMM satellite and Kwajalein oceanic validation site, J. Appl. Meteorol., 39, 2151-2164, 2000.

Sharon, T. M., Albrecht, B. A., Jonsson, H. H., Minnis, P., Khaiyer, M. M., van Reken, T. M., Seinfeld, J., and Flagan, R.: Aerosol and cloud microphysical characteristics of rifts and gradients in maritime stratocumulus clouds, J. Atmos. Sci., 63, 983-997, 2006.

Siggia, A. and Passarelli, R.: Gaussian model adaptive processing (GMAP) for improved ground clutter cancellation and moment calculation, Proc. ERAD, 421-424, 2004.

Stevens, B., Lenschow, D. H., Vali, G., Gerber, H., Bandy, A., Blomquist, B., Brenguier, J.-L., Bretherton, C., Burnet, F., and Campos, T.: Dynamics and chemistry of marine stratocumulus DYCOMS-II, B. Am. Meteorol. Soc., 84, 579-594, 2003.

Stevens, B., Vali, G., Comstock, K. K., Wood, R., Van Zanten, M. C., Austin, P. H., Bretherton, C. S., and Lenschow, D. H.: Pockets of open cells and drizzle in marine stratocumulus, B. Am. Meteorol. Soc., 86, 51-58, 2005.

Stevens, B., Farrell, D., Hirsch, L., Jansen, F., Nuijens, L., Serikov, I., Brügmann, B., Forde, M., Linne, H., and Lonitz, K.: The Barbados Cloud Observatory: Anchoring investigations of clouds and circulation on the edge of the ITCZ, B. Am. Meteorol. Soc., 97, 787-801, 2016. 
Tatarevic, A., Kollias, P., Oue, M., and Wang, D.: User's Guide CR-SIM SOFTWARE v 3.0. McGill University Clouds Research Group, Document, available at: http://radarscience.weebly.com/ radar-simulators.html, last access: 1 July 2019.

Torres, S. M. and Zrnic, D. S.: Ground clutter canceling with a regression filter, J. Atmos. Ocean. Tech., 16, 1364-1372, 1999.

Toyoshima, K., Masunaga, H., and Furuzawa, F. A.: Early evaluation of $\mathrm{Ku}$-and Ka-band sensitivities for the global precipitation measurement (GPM) dual-frequency precipitation radar (DPR), Sola, 11, 14-17, 2015

Unal, C.: Spectral polarimetric radar clutter suppression to enhance atmospheric echoes, J. Atmos. Ocean. Tech., 26, 1781-1797, 2009.

Vali, G., Kelly, R. D., French, J., Haimov, S., Leon, D., McIntosh, R. E., and Pazmany, A.: Finescale structure and microphysics of coastal stratus, J. Atmos. Sci., 55, 3540-3564, 1998.

VanZanten, M., Stevens, B., Vali, G., and Lenschow, D.: Observations of drizzle in nocturnal marine stratocumulus, J. Atmos. Sci., 62, 88-106, 2005.

Villarini, G. and Krajewski, W. F.: Review of the different sources of uncertainty in single polarization radar-based estimates of rainfall, Surv. Geophys., 31, 107-129, 2010.

Wang, H. and Feingold, G.: Modeling mesoscale cellular structures and drizzle in marine stratocumulus. Part I: Impact of drizzle on the formation and evolution of open cells, J. Atmos. Sci., 66, 3237-3256, 2009.

Warren, R. A., Protat, A., Siems, S. T., Ramsay, H. A., Louf, V., Manton, M. J., and Kane, T. A.: Calibrating ground-based radars against TRMM and GPM, J. Atmos. Ocean. Tech., 35, 323-346, 2018

Wood, R.: Drizzle in stratiform boundary layer clouds. Part II: Microphysical aspects, J. Atmos. Sci., 62, 3034-3050, 2005.

Wood, R.: Stratocumulus clouds, Mon. Weather Rev., 140, 23732423, 2012

Wood, R. and Hartmann, D. L.: Spatial variability of liquid water path in marine low cloud: The importance of mesoscale cellular convection, J. Climate, 19, 1748-1764, 2006.
Wood, R., Bretherton, C. S., Leon, D., Clarke, A. D., Zuidema, P., Allen, G., and Coe, H.: An aircraft case study of the spatial transition from closed to open mesoscale cellular convection over the Southeast Pacific, Atmos. Chem. Phys., 11, 2341-2370, https://doi.org/10.5194/acp-11-2341-2011, 2011.

Wood, R., Wyant, M., Bretherton, C. S., Rémillard, J., Kollias, P., Fletcher, J., Stemmler, J., de Szoeke, S., Yuter, S., Miller, M., Mechem, D., Tselioudis, G., Chiu, J. C., Mann, J. A., O’Connor, E. J., Hogan, R. J., Dong, X., Miller, M., Ghate, V., Jefferson, A., Min, Q., Minnis, P., Palikonda, R., Albrecht, B., Luke, E., Hannay, C., and Lin, Y.: Clouds, aerosols, and precipitation in the marine boundary layer: An arm mobile facility deployment, B. Am. Meteorol. Soc., 96.3, 419-440, https://doi.org/10.1175/BAMSD-13-00180.1, 2015.

Yamaguchi, T. and Feingold, G.: On the relationship between open cellular convective cloud patterns and the spatial distribution of precipitation, Atmos. Chem. Phys., 15, 1237-1251, https://doi.org/10.5194/acp-15-1237-2015, 2015.

Yang, F., Luke, E. P., Kollias, P., Kostinski, A. B., and Vogelmann, A. M.: Scaling of drizzle virga depth with cloud thickness for marine stratocumulus clouds, Geophys. Res. Lett., 45, 3746-3753, 2018.

Yuter, S. E., Serra, Y. L., and Houze Jr., R. A.: The 1997 Pan American climate studies tropical eastern Pacific process study. Part II: Stratocumulus region, B. Am. Meteorol. Soc., 81, 483-490, 2000.

Zhou, X., Heus, T., and Kollias, P.: Influences of drizzle on stratocumulus cloudiness and organization, J. Geophys. Res.-Atmos., 122, 6989-7003, 2017.

Zhou, X., Ackerman, A. S., Fridlind, A. M., and Kollias, P.: Simulation of Mesoscale Cellular Convection in Marine Stratocumulus. Part I: Drizzling Conditions, J. Atmos. Sci., 75, 257-274, 2018. 